\title{
Dependent indefinites: the view from sign language
}

\author{
Jeremy Kuhn \\ Institut Jean Nicod, CNRS, Ecole Normal Supérieure
}

November 2, 2016

\begin{abstract}
In many languages, an indefinite determiner or numeral may be inflected to indicate that the value of the indefinite DP depends on another DP in the sentence or in context. Most semantic analyses of dependent indefinites formalize a similar insight: dependent indefinites contribute a variation condition: the value of the variable introduced by the indefinite must vary with respect to the value of another variable in the sentence or in context. The specific implementation of this insight varies in significant ways, notably on the following two fundamental architectural questions:
\end{abstract}

1. Are dependent indefinites anaphoric to their licensor?

2. Are dependent indefinites themselves quantificational?

In this paper, I argue the following: 1) dependent indefinites have an anaphoric component; 2) they are themselves quantificational. I argue that new data involving spatial agreement in American Sign Language gives insight into these questions, but that the answers have theoretical and empirical ramifications beyond sign language. An analysis is presented within the framework of Plural Compositional DRT (Brasoveanu 2006, i.a.).

\section{Overview}

In many languages of the world, an indefinite determiner or numeral may be inflected to create a 'dependent indefinite,' indicating that the value of the indefinite DP depends on another DP in the sentence or in context. In this paper, I will discuss a pattern of dependent indefinites in American Sign Language (ASL), where inflecting an indefinite with reduplication or 'arc' movement generates an interpretation of dependency. In (1), for example, the sentence entails that a plurality of books are distributed over the boys, one each.

(1) BOY IX-arc-a READ ONE-arc-a BOOK.

'The boys read one book each.' 
Most semantic analyses of dependent indefinites (in spoken language) formalize a similar insight: dependent indefinites contribute a variation condition: the value of the variable introduced by the indefinite must vary with respect to the value of another variable in the sentence or in context. The specific implementation of this insight varies in significant ways, notably on the following two fundamental architectural questions:

1. What is the relation between a dependent indefinite and its licensor? Is it anaphoric, or is it indirect?

2. Does the distributive meaning reside in the dependent itself (i.e., is it quantificational), or is it parasitic on a (possibly covert) distributive operator elsewhere in the sentence?

In their licensing patterns and interpretation, dependent indefinites in ASL fit into a broader cross-linguistic typology of dependent indefinites known from spoken language. With the use of space, however, I will show that the ASL pattern is unique in several important ways; I will argue that these unique properties bear on the questions above. First, ASL overtly represents the dependency relation between a dependent indefinite and its licensor. In ASL, plural DPs may be indexed over areas of space in the horizontal plane in front of the signer (indicated in glosses by lowercase letters ' $a$ ' and 'b'). Dependent indefinites are obligatorily signed over the same area of space as their licensor. In (1), for example, the indefinite ONE moves over the same area of space that was established for the boys (area ' $a$ '). I will argue that this provides evidence for a direct anaphoric relation between a dependent indefinite and its licensor. Second, the spatial marking of dependency on numerals also appears on the adjectives SAME and DIFFERENT, motivating a unified account of the inflection in each case. The adjectives SAME and DIFFERENT must be given an inherently quantificational meaning; by generalization to the worst case, I will argue that dependent indefinites must be inherently distributive as well.

With these facts established, we turn to a third compositional puzzle - namely, how are dependent indefinites able to 'see outside' the scope of a distributive operator? To answer this question, we adopt Henderson 2014's proposal to move to a dynamic semantics with plural information states (Dynamic Plural Logic: van den Berg 1996, Nouwen 2003; Plural Compositional DRT: Brasoveanu 2006, 2013). The advantage of these frameworks is that a predicate that is evaluated after the scope of a distributive operator has closed is nevertheless still able to access the functional associations established under the distributive operator. While I will maintain the general insight from Henderson 2014 (i.e., evaluation after scope has closed), the implementation will differ. Specifically, I will show that my answers to the architectural questions above allow us to simplify the mechanism of scope-taking: instead of using Henderson 2014's mechanism of 'postsuppositions' (Brasoveanu 2013), I will propose that dependent indefinites take scope through standard quantifier raising. Empirical consequences of these design choices will be evaluated. 


\subsection{Methodology}

This paper presents novel data from both American Sign Language and from various spoken languages. Sign language data were gathered primarily through consultation with one native signer (a Deaf child of Deaf signing adults), and were replicated with a second signer. Judgments were gathered following the 'playback method' (Schlenker 2011). The signer was asked to sign a paradigm of sentences for a video recording. The resulting video was then played back for the same signer, who gave grammaticality judgments using a 7-point scale $(7=$ best $)$ and answers to any interpretation questions. Judgments could then be repeated on separate days. Generalizations in the present paper are based on at least two ratings of a construction by the principle consultant plus replication with the second consultant.

Because judgments on the 7-point scale showed a clear bimodal distribution, gradient judgments are suppressed here in favor of the conventional binary scale (with '*' indicating ungrammaticality). For the primary consultant, all sentences reported here as grammatical received an average score of 6.5 or higher; sentences reported here as ungrammatical received an average score between 2.5 and 3.6. For the second consultant, all scores were depreciated, perhaps due to the unnaturalness of the task of giving grammaticality judgements (the maximum score for any sentence reported here was a 5, including for sentences invented by the consultant themself as 'good sentences'). Nevertheless, there was still a clear bimodal distribution; all sentences reported as ungrammatical here (marked as '*') received a score of 0 or 1 (the score of 0 was added by the consultant); all other sentences received a score between 3 and 5. The two consultants answered uniformly to interpretation questions.

Replication of spoken language data is reported in the body of the paper.

\section{Dependent indefinites in ASL: visible dependency}

\subsection{Dependency marking in ASL}

Natural language has a number of ways of morphologically marking dependency. When such inflection appears on an indefinite determiner or numeral, the resulting noun phrase is called a dependent indefinite (or dependent numeral) ${ }^{1}$. Broadly speaking, the word or suffix imposes a 'variation condition' that the NP that it attaches to varies with respect to another NP in the sentence or in context.

For example, in Telugu, reduplication of a numeral creates a dependent indefinite (Balusu 2006): the sentence in (2) carries the meaning that the pairs of monkeys vary with respect to the boys. Reduplicated numerals in Kaqchikel Mayan behave similarly: reduplication of $o x$, 'three,' in (3) generates the meaning that there are three tortillas per individual.

(2) Telugu (Balusu 2006)

\footnotetext{
${ }^{1}$ The term 'distance distributivity' has been used to encompass a wider range of phenomena; additionally including participant-key readings of pluractionals and perhaps also the internal readings of same and different.
} 
pilla-lu renDu-renDu kootu-lu-ni cuus-ee-ru.

kids two-two monkey-Pl-Acc see-Past-3PPL

'(The) kids saw two monkeys each.'

(3) Kaqchikel Mayan (Henderson 2014)

Xeqatij ox-ox wäy.

we-eat three-three tortilla

'We each ate three tortillas.'

In American Sign Language, too, indefinite determiners and numerals may be inflected to indicate dependency. In their semantic interpretation, their licensing conditions, and even morphological marking via phonological reduplication (as in Telugu and Kaqchikel), we will see that dependent indefinites in ASL fit into a broader cross-linguistic pattern of dependent indefinites. In ASL, however, plurality marking critically employs the use of space; this use of space adds an extra dimension to the patterns of dependency.

In American Sign Language, singular individuals may be indexed at points in space. For example, if a signer is talking about some individual, Mike, who's not in the conversation, the signer can index him at a location in space; he or she can then refer back to him later by directing a pronoun at the location where Mike was established (Lillo-Martin and Klima 1990, i.a.). Plurality may be indicated by moving a sign over an area of space. The images in (4) illustrate two ways of morphologically marking plurals: either with a sweeping 'arc'-motion, or with a repeated or reduplicated movement across the area of space. Plural marking has been shown to appear cross-categorially, on nouns, pronouns, verbs, and, as will be important here, numerals and adjectives (See Wilbur 1973 for ASL, Pfau and Steinbach 2006 for related phenomena in German Sign Language).

a. Arc-movement

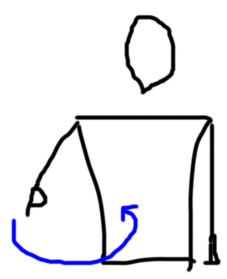

b. Reduplication

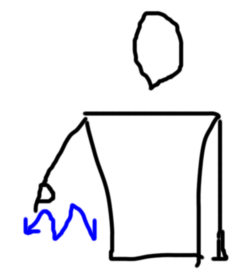

In ASL, the uninflected form of a numeral is signed by holding a hand in place, with an interpretation parallel to plain indefinites in English. When numerals are inflected with plural marking (either arc-movement or reduplication ${ }^{2}$ ), their interpretation becomes like that of dependent indefinites in spoken languages: analogously to (2), the ASL sentence in (5) entails that the books vary with respect to the boys: each boy read a potentially different book.

BOYS IX-arc-a READ ONE-arc-a BOOK.

'The boys read one book each.'

\footnotetext{
${ }^{2}$ I have observed no semantic difference between arc-movement and reduplication when it appears on dependent indefinites, so ONE-arc and ONE-redup can be viewed as synonymous. I will nevertheless retain the distinction in glosses, not wishing to collapse what could in principle be a morphological distinction.
} 
The variation condition has the effect of ruling out collective readings of the plural licensor, where a single event is performed by a group of individuals. For example, the sentence with a plain indefinite in (6a) may receive either a distributive reading (where each boy lifted a table individually) or a collective reading (where the boys lifted a table together), but the sentence with a dependent indefinite in (6b) may only receive a distributive reading.

a. ALL BOY LIFT ONE TABLE.

$\checkmark$ collective $\checkmark$ distributive

'All the boys lifted a table.'

b. ALL BOY LIFT $\{$ ONE-arc/ONE-redup $\}$ TABLE. $\quad *$ collective $\checkmark$ distributive

'The boys each lifted a table.'

\subsection{Overt spatial dependency}

In their semantic interpretation-and, indeed, in their morphological marking via reduplication-dependent indefinites in ASL fit into a broader cross-linguistic pattern of dependent indefinites. With the use of space, however, ASL is unique in that it is able to overtly represent the dependency relation between a dependent indefinite and its licensor. In ASL, plural DPs may be indexed over areas of space in the horizontal plane in front of the signer (indicated in glosses by lowercase letters a and b). Dependent indefinites are obligatorily signed over the same area of space as their licensor.

The minimal pair in (7) and (8) illustrates this obligatory agreement. In (7), the dependent indefinite ONE-redup agrees in space with the location of the licensor EACH PROFESSOR (location ' $a$ '); the result is a grammatical sentence with a distributive meaning. In contrast, in (8), the dependent indefinite moves over a different area of space (location ' $b$ '). The result is degraded grammaticality (avg. 4.5/7 for primary consultant; 4/7 for secondary consultant); to the extent it is acceptable, it must mean that the students vary with respect to some contextually salient plural that was previously established at location $b$.

EACH-a PROFESSOR SAID ONE-redup-a STUDENT WILL RECEIVE B. 'Each professor said that one student will receive a B.'

? EACH-a PROFESSOR SAID ONE-redup-b STUDENT WILL RECEIVE B.

'Each professor said that one student per contextually salient group will receive a B.'

Empirically, obligatory agreement between a dependent indefinite and its licensor means that sign language is able to disambiguate readings where spoken language cannot. In particular, when a dependent indefinite appears in a sentence with two potential licensors, the indefinite can in principle depend on either one. In at least Hungarian and Albanian, this is exactly what is attested. Consultants were asked to whether the sentences in (9)/(10) could be used felicitously to describe situations with either collective giving or collective receiving. A collective giving event would be one where the boys as a group gave Mary two books, the boys as a group gave Ellen two books, etcetera; a collective receiving event would be one where John gave two books to the group of girls, Bill gave two books to the group of girls, and so on. In both languages, the 
relevant sentence was judged as allowing both readings (but not a fully collective reading with two books total); the dependent indefinite thus allows distribution over either licensor.

(9) Hungarian (p.c. Dániel Szeredi; three speakers)

A fiúk két-két könyvet adtak a lányoknak.

The boys two-two book give.3Pl the girls

'The boys gave the girls two books $\{$ per boy OR per girl $\}$.'

(10) Albanian (p.c. Bujar Rushiti, one speaker)

Djemtë u dhanë vajzave nga dy libra.

boys 3Pl.Dat gave girls DIST two books

'The boys gave the girls two books $\{$ per boy OR per girl\}.'

In contrast, an analogous sentence in ASL can be completely disambiguated with the use of space. In (11), the boys are signed at location a; the girls are signed at location b. By moving over location $b$, the dependent indefinite ONE-arc is unambiguous: the sentence can only refer to a situation with distribution over the girls (e.g., a 'collective giving' event).

ALL-a BOY GAVE ALL-b GIRL ONE-arc-b BOOK.

'All the boys gave all the girls one book per girl.'

Analogous sentences can be constructed in which ONE-arc agrees with the boys, disambiguating the other direction.

\subsection{Theoretical import: overt anaphoricity}

We now address the first architectural question introduced above:

1. What is the relation between a dependent indefinite and its licensor?

In the literature on dependent indefinites, and more generally on long-distance dependency (including the adjectives same and different), two approaches have been taken to this question.

In the first camp, dependent indefinites are analyzed as bearing an anaphoric link to their licensor. On this view, the relation between the two is analogous to the relation between a bound pronoun and its binder: the compositional system represents a formal link between the two constituents. Such a position has been proposed by Brasoveanu \& Farkas 2011 for dependent indefinites, and, expanding the view to general distance-distributivity, by Brasoveanu 2011 for singular different in English. Barker 2007's analysis of same also falls into this camp, in that the dependent expression must take parasitic scope on a specific licensor.

In the second camp, the relation between dependent indefinites and their licensor is indirect. On this view, the relation between the two is analogous to the relation between a negative polarity item and its licensor (Kadmon and Landman 1993): for example, an NPI like ever must appear in a downward entailing environment (roughly speaking), but it does not matter how 
the compositional system generated this environment. Such a position has been advocated for dependent indefinites by Balusu 2006, Henderson 2014, and Cable 2014.

The new data from ASL allows us to answer this debate. Even if some languages don't use the system's full expressiveness, the ASL data is overtly anaphoric. The general apparatus for dependent indefinites must thus be sufficiently powerful to represent this connection.

\section{A compositional puzzle: whence the distributive force?}

\subsection{Licensing dependent indefinites}

A key property of dependent indefinites regards the environments in which they are licensed. In many unrelated languages, dependent indefinites show the same licensing patterns: they are licensed under a plural or a distributive operator, but are ungrammatical when all other arguments are singular. This generalization holds of dependent indefinites in Kaqchikel (Henderson 2014), Hungarian (Farkas 1997), Romanian (Brasoveanu \& Farkas 2011), Albanian (Rushiti 2015), in some dialects of English (Champollion 2015), and in ASL (this work). In Telugu (Balusu 2006), the situation is slightly more complicated, since a dependent indefinite may indicate distribution of the NP over time or space (a 'temporal key' or 'spatial key' reading), in which case it needs no licensor. However, on the 'participant key' reading, in which the dependent indefinite indicates distribution of the NP with respect to another NP in the sentence (the only reading available in the other languages), Telugu reflects the same pattern as we see elsewhere: it is only possible with a plural or distributive licensor. ${ }^{3}$

The examples in (12)-(16) demonstrate this pattern with five unrelated languages. In each case, the same pattern holds: (a) and (b) are grammatical; (c), with no plural or distributive licensor, is ungrammatical (or, in the case of Telugu, ungrammatical on the relevant reading).

(12) Kaqchikel Mayan (Henderson 2014)
a. Xeqatij ox-ox wäy.
we-eat three-three tortilla
'We each ate three tortillas.'
b. Chikijujunal ri tijoxela' xkiq'etej ju-jun tz'i'. each the students hugged one-one dog
'Each of the students hugged a dog.'
c. * Xe'inchäp ox-ox wäy.
I-handle three-three tortilla
Desired reading: 'I took (groups of) three tortillas.'

\section{(13) Telugu (Balusu 2006)}

\footnotetext{
${ }^{3}$ Russian -nibud' seems to be an exception to this generalization, being only licensed by an overt distributive operator (Yanovich 2005).
} 
a. pilla-lu renDu-renDu kootu-lu-ni cuus-ee-ru.

kid-Pl two-two monkey-Pl-Acc see-Past-3PPl

'(The) kids saw two monkeys each.'

Two readings: 'participant key' and 'temporal key.'

b. Prati pillavaaDu renDu-renDu kootu-lu-ni cuus-ee-Du.

Every kid two-two monkey-Pl-Acc see-Past-3PSg

'Every kid saw two monkeys (each).'

Two readings: 'participant key' and 'temporal key.'

c. Raamu renDu-renDu kootu-lu-ni cuus-ee-Du.

Ram two-two monkey-Pl-Acc see-Past-3PSg

'Ram saw two monkeys each.'

Only 'temporal key' reading.

(14) Albanian (Rushiti 2015)

a. Fëmijët kanë parë nga pesë mace.

children-the have seen DIST five cats

'The children have seen five cats each'

b. Në çdo dhomë kishte nga dy fotografi.

in every room there-were $\overline{\mathrm{DIST}}$ two photos

'There were two (different) photos in each room'

c. * Në dhomë kishte nga dy fotografi.

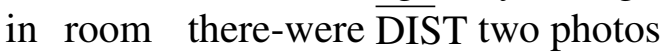

Desired reading: 'There were two (different) photos in the room.'

\section{(15) English}

a. The boys saw two zebras each.

b. \% Every job candidate was in the room for fifteen minutes each. ${ }^{4}$

c. * Ariella saw two zebras each.

(16) ASL

a. BOYS IX-arc-a READ ONE-arc-a BOOK.

'The boys read one book each.'

b. EACH-EACH-a PROFESSOR NOMINATE ONE-redup-a STUDENT.

'Each professor nominated one student.'

c. * JOHN-a READ ONE-arc-a BOOK.

Desired reading: 'John read one book.'

What is compositionally challenging about this pattern is that quantifiers like every in English distribute down to atomic individuals, as evidenced by their ungrammaticality with collective predicates like gather, as in (17). The distributive operators discussed for other languages

\footnotetext{
${ }^{4}$ I use the symbol \% to express a dialectal split regarding the judgment of this sentence. For more on the grammaticality of binominal each under distributive operators in English, see Szabolcsi 2010, Ch. 8, Bauman et al. 2012, and Champollion 2015.
} 
are parallel: (18) presents data from ASL; Henderson 2014 (f.n. 14) gives analogous data for Kaqchikel chikijujunal.

\section{(17) English}

a. The boys gathered.

b. * Every boy gathered.

c. * Edith gathered.

(18) ASL
a. MY FRIENDS, IX-arc-a GATHER.
'My friends gathered.'
b. * EACH STUDENT MY CLASS GATHER.
'Each student in my class gathered.'
c. * JOHN GATHER.
'John gathered.'

As discussed by a number of authors (e.g. Balusu 2006, Oh 2006), dependent indefinites under distributive operators seem to be puzzlingly redundant. That is, with a plural licensor, these morphemes seem to contribute distributive force themselves, but under distributive operators, they appear to be semantically vacuous. What, then, is the semantic contribution of the dependent indefinite? In particular, if there are certain cases in which they are semantically vacuous, then why can't they appear innocently under singular subjects?

\subsection{Two possible directions}

Ultimately, the puzzle reduces to the second architectural question introduced above:

2. Does the distributive meaning reside in the dependent itself (i.e., is it quantificational), or is it parasitic on a (possibly covert) distributive operator elsewhere in the sentence?

The issue can thus be made more concrete by outlining the two possible directions that an analysis can take.

Under option one, licensing by distributives (as in the (b) sentences above) is taken to be the 'base case.' Dependent indefinites are non-quantificational, with an at-issue meaning equivalent to that of a plain indefinite. What characterizes a dependent indefinite is that a syntactic or semantic constraint (e.g. 'distributive concord') requires the indefinite to scope under a distributive operator. Licensing by plurals (as in the (a) sentences) must thus arise via a covert distributivity operator, as in (19).

(19) The boys DIST [saw two-two zebras].

A version of this hypothesis is adopted by Brasoveanu and Farkas 2011 and Henderson 2014.

Under option two, licensing by plurals (as in the (a) sentences) is taken to be the 'base case.'

On such an analysis, the at-issue meaning of a dependent indefinite is itself distributive, with a quantificational lexical entry like the one sketched in (20). 
【two-two books $\rrbracket=$ Given a licensor $X$, presupposing that $X$ is nonatomic, for all atomic parts $x$ of $X$, there are two books associated with $x$

For a dependent indefinite to be licensed by a distributive operator (as in the (b) sentences), the indefinite must be able to able to 'escape' from the distributive scope, to get access to a higher plurality that is made available by the compositional system. A version of this hypothesis is adopted by Balusu 2006 and Cable 2014.

\subsection{A problem for non-distributivity (option 1)}

An undergeneration problem for the non-distributive analysis of dependent indefinites comes from new facts regarding coordination. On an account in which dependent indefinites bear the same at-issue meaning as plain indefinites (i.e., they are non-quantificational), we saw that licensing by a plural requires the presence of a covert distributivity operator. This makes predictions for examples in which a dependent indefinite is conjoined with a plain indefinite. Specifically, distributive operators are generally assumed to appear over the VP (see, e.g., Dowty and Brodie 1984, Roberts 1987, and Schwarzschild 1996). Thus, if a dependent indefinite scopes under a covert distributive operator, a conjoined plain indefinite must do so, too, receiving a similarly distributive reading.

This is not what we find; in at least Hungarian and Tamil, plain indefinites that are conjoined with dependent indefinites may nevertheless receive cumulative and collective readings. For the sentences in (21) and (22), this can be read off the truth conditions from the number of appetizers or desserts that the students end up with at the end of the day; on the most natural reading the Hungarian sentence entails that there are two appetizers total and the Tamil sentence, two desserts total. An analysis with a covert distributivity operator incorrectly predicts that there should be twice as many as there are students.

(21) Hungarian (p.c. Dániel Szeredi, four speakers)

A diákok két előételt és egy-egy főételt rendeltek. The students two appetizers and one-one main-dish ordered 'The students ordered two appetizers, and $\mathrm{N}$ main dishes where $\mathrm{N}$ is the \# of students.'

(22) Tamil (Chennai dialect) (p.c. Anushree Sengupta, one speaker)

Mānavarkkal thankalai kaga oru-oru appetizer o irenDu desserts share-panna order pannagu. students themselves for one-one appetizer and two desserts share-do order did 'The students ordered one appetizer each for themselves and two desserts to share.'

On the other hand, if dependent indefinites are themselves quantificational, no covert distributivity is necessary.

(We note that on theories in which covert distributivity appears directly on DPs, such as Beghelli \& Stowell 1997 and Dotlačil 2011, the above data are also not a problem, since a covert distributivity operator may appear directly on the conjunct that contains the dependent indefinite.) 


\subsection{Support for quantification (option 2): unification with same}

Here, I will show that dependent indefinites in ASL bear strong morphological and spatial similarity to the adjectives SAME and DIFFERENT, motivating a unified analysis. I will consequently argue that this morphological parallel provides support for an analysis in which dependent indefinites are given an inherently quantificational denotation. In $\S 5.4$, I will make the unification concrete, by sketching an extension of my proposal for dependent indefinites to the adjective same.

Before getting to ASL, we observe that English same, too, shares formal features with the patterns of dependent indefinites that we have seen. The adjective same is known to be ambiguous between two meanings: an 'external' reading, which indicates comparison with another individual in context, and an 'internal' reading, which indicates comparison between the members of a licensor. On the internal reading, we observe that the distribution of same is exactly that of the dependent indefinites reviewed in (12)-(16): they can be licensed by both plurals and distributive operators, but are ungrammatical with singulars. See $\S 6.2$ of Barker 2007 for discussion of this puzzle.

(23) English same (on internal reading):

a. The students gave the same answer.

b. Each student gave the same answer.

c. * Edith gave the same answer.

If the English licensing data hints that same should be treated similarly to dependent indefinites, the ASL data hits you over the head with the idea. In ASL, both SAME and DIFFERENT can be signed in a neutral form, as shown in Figure 1: SAME vibrates back and forth in place; DIFFERENT shows a single movement.

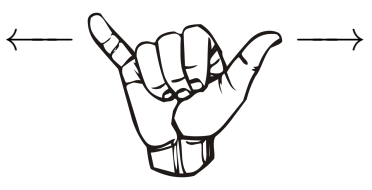

SAME

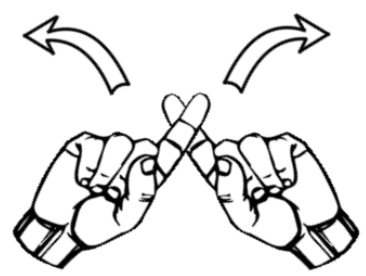

DIFFERENT

Figure 1: Neutral SAME and DIFFERENT in ASL

As with ASL numerals, both SAME and DIFFERENT can additionally be inflected to move over an area of space: SAME with arc-movement, DIFFERENT with reduplication. As with dependent indefinites, this movement shows obligatory spatial agreement with the licensor, and generates an interpretation of dependency. The paradigm in (24) illustrates this parallel with three sentences; in each, the dependent term moves over the area of space, location a, where the 
licensor was indexed. Critically, the sentences in (24b) and (c) only admit an internal reading, in which the boys read the same book as each other or different books from each other ${ }^{5}$.
a. ALL-a BOY READ ONE-arc-a BOOK.
'All the boys read one book.'
b. ALL-a BOY READ SAME-arc-a BOOK.
'All the boys read the same book.'
c. ALL-a BOY READ DIFFERENT-redup-a BOOK.
'All the boys read a different book.'

As with dependent indefinites, the spatial representation of dependency for same and different has the result of disambiguating sentences that are ambiguous in spoken language. Specifically, Bumford and Barker 2013 show that sentences with same and different are ambiguous in sentences with are multiple potential licensors. For example, the English sentence in (25) can be used to describe a scenario in which each boy bought many copies of the same book, and distributed them to the girls (in which case, every girl is the licensor), or a scenario in which each girl received many copies of the same book from the various boys (in which case, every boy is the licensor). An analogous ambiguity holds for (26).

(25) Every boy gave every girl the same book.

(26) Every boy gave every girl a different book.

(Bumford and Barker 2013)

In ASL, the use of space removes this ambiguity. In (27), the boys are established over location $a$, and the girls are established over location $b$; the adjective SAME moves in space over location $b$. In a context-matching task, consultants were asked whether the sentence could be used to describe each of the scenarios described for the English sentence above. The only admitted meaning was the one in which 'sameness' is distributed with respect to the girls: John gave all the girls the same book, Bill gave all the girls the same book, and so on. The other reading can be specified with a related sentence in which SAME-arc moves over location a, where the boys were indexed. Analogous results hold for DIFFERENT.

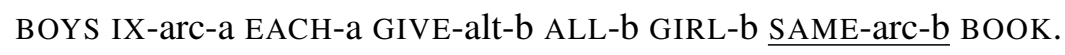

'The boys each gave all the girls the same book (with respect to the girls).'

With the goal of ultimately providing a unified analysis of spatial inflection in all three of these cases, we reach the theoretical conclusion that dependent indefinites and the adjectives same and different should be treated in fundamentally the same way.

We are now in a position to address the at-issue meaning of dependent indefinites, through analogy with same and different. Consider the meaning of same. As for dependent indefinites,

\footnotetext{
${ }^{5}$ One notable difference holds between DIFFERENT and the other two dependent terms: inflected DIFFERENT may appear over an area of space without any licensor. The resulting meaning is analogous to the meaning of different in the English sentence 'John read a bunch of different books.' Nevertheless, when DIFFERENT agrees with a licensor, the only available reading is the internal reading where there is comparison with respect to the licensor.
} 
same induces dependency (of events) on a licensor. For example, in a sentence like (28a), we infer that there is a different table-lifting for each boy; in this sense, there is variation with respect to the licensor. But of course, this is only one part of the adjective's meaning: additionally, same compares the tables lifted by each boy, and entails that they are identical. The meaning of (28a) can thus be restated as in (28b). Critically, this meaning of same is inherently quantificational.

a. Every student lifted the same table.

b. For each pair of boys, they lifted the same table.

We have seen that dependent indefinites and SAME and DIFFERENT in ASL are strongly morphologically united with the use of space, from which we concluded that they should be analyzed on a par. We have seen that same (in English as in ASL) must be given an inherently quantificational meaning. By analogy, we conclude that dependent indefinites must receive an inherently quantificational meaning as well.

\subsection{The proposal in a nutshell}

The following two sections present a formal proposal for dependent indefinites. The proposal is summarized here. Dependent indefinites introduce a plurality into a discourse. They consist of two components of meaning:

1. Presupposition: the plurality can be divided into subpluralities that vary with respect to the atoms of a licensor.

2. At-issue: each of these subpluralities is of a given cardinality.

Here, the fact that dependent indefinites are anaphoric can be seen in the fact that the definitions make direct reference to the licensor. The fact that they are quantificational can be seen in the fact that the at-issue component universally quantifies over subpluralities.

Finally, licensing by distributives like each is achieved by quantifier raising of the dependent indefinite, letting it scope outside the distributive operator. Critically, the framework of Plural Compositional DRT allows the semantics to be able to make reference to functional dependencies even outside of the distributive scope.

\section{Dependency in Plural Compositional DRT}

The analysis presented here will be implemented within Plural Compositional Discourse Representation Theory (PCDRT: Brasoveanu 2006), a form of dynamic semantics that is designed to keep track of relationships between plural discourse referents. PCDRT is based on the related framework of Dynamic Plural Logic (DPIL: van den Berg 1996); these two systems have been explored in a collection of recent work including van den Berg 1996, Nouwen 2003, Brasoveanu 2008, 2013, Henderson 2014, and Champollion 2015. From the point of view of ASL, PCDRT 
presents an attractive formalism because it provides a way to dynamically build functional discourse referents through the semantic association of two plurals-in other words, exactly the kind of operation that seems to be visibly overt in the ASL paradigms discussed above.

Several technical notes are warranted on the formalism below. First, van den Berg 1996 and Nouwen 2003 provide a trivalent semantics for DPIL, defining conditions for truth, falsity, and undefinedness. Since this does not play a critical role in my discussion here, I will follow Brasoveanu 2013 and Henderson 2014 in defining only the conditions for the truth of a given proposition in PCDRT. The interested reader is referred to Nouwen 2003 for more discussion of undefinedness in DPIL. Second, I will be providing a definition for conjunction that allows information to pass asymmetrically through the discourse; to avoid overloading notation, ' $\wedge$ ' will be used for dynamic conjunction; ' $\&$ ' will be used for classical boolean conjunction. Finally, to avoid overloading the term 'variable,' I adopt the term 'index' to refer to the type of the objects in the domain of an assignment function. Thus, the indices $x, y$, and $z$ are objects in the object language; I use $i, j, k$, and $l$ in the metalanguage as variables over these indices.

\subsection{Background: Plural Compositional DRT}

In dynamic semantics, sentence meanings are modeled as functions that change the context in some way; most notably, they can add new discourse referents into the context. In standard dynamic semantics (Groenendijk \& Stokhof 1991, Dekker 1993), active discourse referents are formally represented as the values of an assignment function-informally speaking, an infinite list of individuals - that is passed from sentence to sentence through the discourse. The output context of one sentence serves as the input context of the next sentence. Certain operators, including indefinites, can introduce new discourse referents by changing the value of some index. Pronouns retrieve elements from the assignment function.

For example, in (29), both indefinites ('a boy' and 'a girl') introduce a new individual into the discourse context by modifying the assignment function at some index. Evaluating the first sentence yields the set of all the possible outputs that are compatible with the sentence. These outputs then serve as the possible inputs for the second sentence, which updates the context again. Figure 2 shows the effect of updating a context with each of the sentences in (29). (Here, the irrelevant initial values of $x$ and $y$ are the dummy values $\diamond$ and $\star$.) Notationally, following Brasoveanu 2008, I use a superscript on an expression that introduces a discourse referent (' $\mathrm{a}^{y}$ girl') and I use a subscript on an expression that retrieves a discourse referent ('she ${ }_{y}^{\text {') }}$.

(a) $\mathrm{A}^{x}$ boy entered. (b) $\mathrm{A}^{y}$ girl exited. (c) She $\mathrm{S}_{y}$ was angry.

Within a dynamic system, particular operators may themselves be dynamic or static, based on their contribution to the sentence: dynamic operators change the context; static operations only test to see if certain conditions are met. For example, the sentence 'A girl exited' is dynamic, because it adds a new individual into the discourse that can be referred to later. This can be seen in the assignment of a new index in the transition in Figure $2 b$. In contrast, the sentence 'She was angry' is static; it merely filters the input contexts by imposing the condition that the value of some previously defined index has a certain property. Assuming that Alicia 


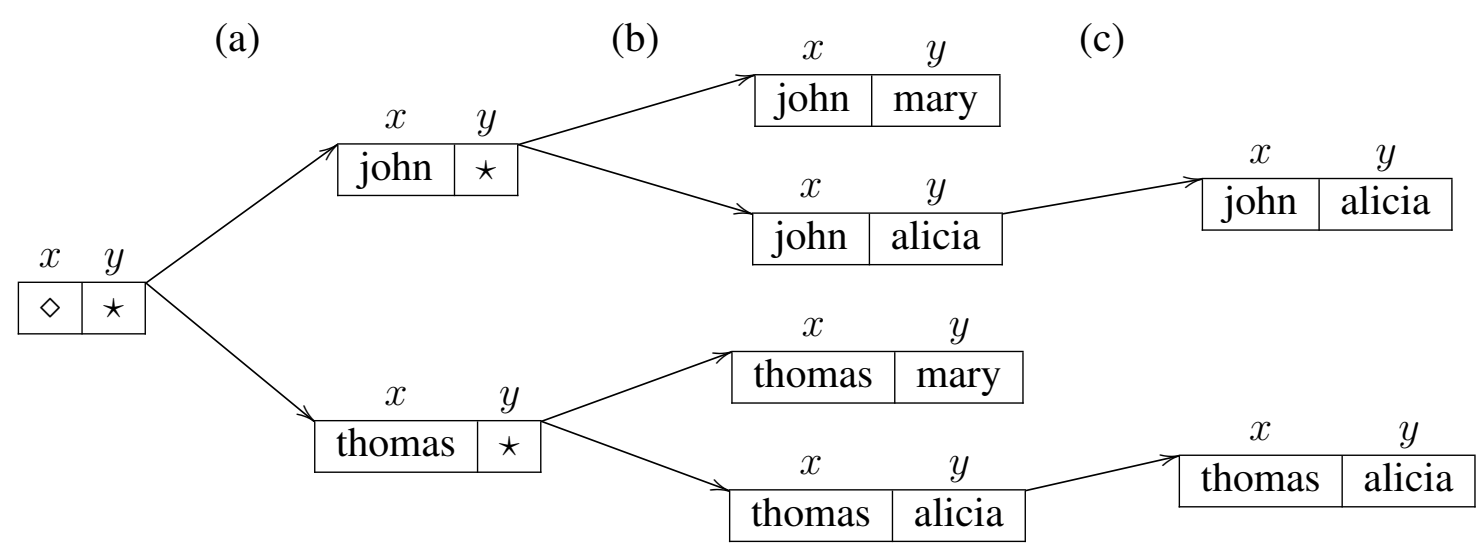

Figure 2: Dynamic updates of the sentences in (29)

was angry but Mary was not, the result is the transition in Figure 2c, which returns a subset of its input contexts.

In standard dynamic semantics, distributive quantifiers like every and each are taken to be 'externally static,' collapsing all new indices that are introduced in their scope, making them unavailable for later sentences. At a first approximation, this seems to be a correct generalization: as seen in (30), an indefinite in the scope of a universal can't serve as the antecedent for an individual pronoun.

* Every ${ }^{x}$ farmer owns $\mathrm{a}^{y}$ donkey. $\mathrm{It}_{y}$ kicked me in the shin.

The difference between an indefinite (which can change the context) and a universal (which can't) is clear in their definitions in Dynamic Predicate Logic (Groenendijk \& Stokhof 1991). In particular, the fact that the universal is externally static can be seen in its requirement that ' $h=g$ ' in (31b), that is, that the output context of the sentence as a whole is the same as its input context.

(31) $\exists$ and $\forall$ in Dynamic Predicate Logic (Groenendijk \& Stokhof 1991)

a. $\llbracket \exists x \varphi \rrbracket=\{\langle g, h\rangle \mid \exists k: k[x] g \quad \& \quad\langle k, h\rangle \in[\varphi]\}$

b. $\llbracket \forall x \varphi \rrbracket=\{\langle g, h\rangle \mid \underline{h=g} \quad \& \quad \forall k: k[x] h \rightarrow \exists j:\langle k, j\rangle \in[\varphi]\}$

To see how the definition in $\forall x \varphi$ works, consider the first sentence of (30). The truth conditions are arrived at by considering the set of assignment functions where $x$ is assigned to a farmer. If each assignment function considered satisfies the test that $x$ owns a donkey (in the process, adding a donkey as the value for $y$ ), then the original input assignment is passed along as an output context (without the added values for $x$ and $y$ ). If any assignment function fails the test, it is not.

It turns out, however, that it is possible to anaphorically access a index introduced in the scope of a distributive quantifier-but only in certain environments. These cases of 'quantificational subordination' (terminology from Heim 1990, Brasoveanu 2006) require a very particular configuration: in the antecedent sentence, an indefinite scopes below a distributive quantifier; 
in the subsequent sentence, a pronoun scopes below an operator that quantifies over the same set as the original distributive quantifier. Sentence (32) provides an example.

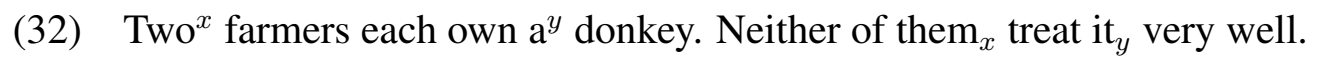

Observe, in (32), that the prounoun it is anaphoric to the indefinite a donkey, yet it refers neither to a single particular donkey nor to the set of all donkeys; rather, it varies with respect to the farmer in question. Moreover, this is not some arbitrary new correspondence between farmers and donkeys; it must be the same correspondence that was introduced by the first sentence. The sentences entail that whichever donkey is owned by a farmer, that is the donkey that he doesn't treat well.

As we have just seen, in standard dynamic semantics, the evaluation of a universal quantifier tests each of a set of assignments; if these are satisfied, it closes the scope of the universal, and discards the assignments it built along the way. Essentially what the example in (32) shows is that we need to be able to 're-open' the scope of a universal, to see what the value of $y$ was for each value of $x$ in the intermediate computation. In other words, we need to store all the assignment functions that were used in the evaluation of a universal quantifier.

Plural Compositional DRT (following Dynamic Plural Logic) is an enrichment of dynamic semantics that does exactly this: instead of passing assignment functions through the discourse, it passes sets of assignment functions. This allows dependency relationships to be formally represented and stored. As before, the evaluation of a universal quantifier tests each of a set of assignments; in PCDRT, if these are satisfied, it collects them and adds the entire set to the discourse context. Figure 3 shows the effect of updating a neutral context with each of the sentences in (32) in PCDRT.

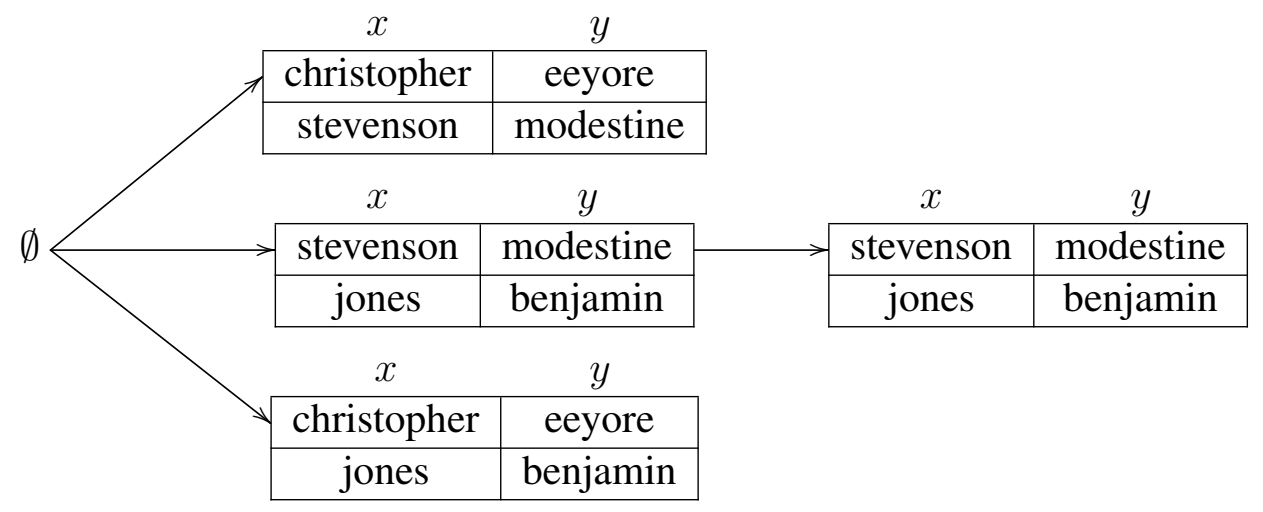

Figure 3: Dynamic updates of the sentences in (32) in PCDRT

We will call these sets of assignment functions 'information states.' These representations can be thought of as the contexts that verify the sentence that generated them. 


\subsection{Formally defining information states (and dependency)}

We use $g$ and $h$ as variables over assignment functions. We use $G$ and $H$ as variables over sets of assignment functions ('information states,' essentially, tables of individuals). Assignment functions are taken to be total assignments, so technically contain infinitely many values that are irrelevant to the computation of a sentence. Since these values will not interact in the derivations here, we will adopt a convention in which information states are depicted with only the indices that have had their values accessed by a linguistic operator. So, assuming that a linguistic discourse has modified the values of $x$ and $y$ and not accessed the values of any other indices, we will use the table shown in (33a) as a shorthand for the table in (33b).

a.

\begin{tabular}{c|c|c|}
\multicolumn{1}{c}{$x$} & $y$ \\
$g_{1}:$ & $\mathrm{a}$ & $\mathrm{c}$ \\
\cline { 2 - 3 }$g_{2}:$ & $\mathrm{b}$ & $\mathrm{d}$ \\
\hline
\end{tabular}

b.

\begin{tabular}{|c|c|c|c|c|}
\hline \multirow{3}{*}{$g_{1}: \quad \ldots$} & $w$ & $x$ & $y$ & $z$ \\
\hline & junk1 & $\mathrm{a}$ & c & junk3 \\
\hline & junk2 & $\mathrm{b}$ & $\bar{d}$ & junk4 \\
\hline
\end{tabular}

The following definitions provide a way to refer to subparts of these tables. $G(x)$, returns the set of values taken by the index $x$ in an information state $G$-roughly, a vertical slice of the table. $\left.G\right|_{x=d}$ (read: ' $G$ with $x$ restricted to $d$ '), returns a substate consisting of those assignment functions in $G$ where $x$ is assigned to $d$.

(34) Definition:

$G(x) \quad:=\quad\{g(x) \mid g \in G\}$

'the set of values in the $x$-column of a table'

\section{(35) Definition:}

$\left.G\right|_{x=d} \quad:=\quad\{g \mid g \in G \& g(x)=d\}$

'the rows of a table where $x$ is assigned to $d$ '

For example, if $G$ is the information state in (36a), then (36b) provides $G(y)$ and (36c) provides $\left.G\right|_{x=\mathrm{a}}$.
a. $G=$\begin{tabular}{|l|l|}
$x$ & $y$ \\
\hline $\mathrm{a}$ & $\mathrm{c}$ \\
\hline $\mathrm{a}$ & $\mathrm{d}$ \\
\hline $\mathrm{b}$ & $\mathrm{d}$ \\
\hline $\mathrm{e}$ & $\mathrm{f}$ \\
\hline
\end{tabular}
b. $G(y)=\{\mathrm{c}, \mathrm{d}, \mathrm{f}\}$

$\begin{aligned} & \text { c. }\left.G\right|_{x=\mathrm{a}}= x \quad y \\ &$\[ \begin{array}{|l|l|}\hline \mathrm{a} & \mathrm{c} \\ \hline \mathrm{a} & \mathrm{d} \\ \hline\end{array} \]$\end{aligned}$

Using these definitions, we can now introduce a formal definition of dependency.

(37) In an information state $G, y$ is dependent on $x$ iff

$$
\exists d, e \in G(x) .\left.G\right|_{x=d}(y) \neq\left. G\right|_{x=e}(y)
$$

(Nouwen 2003, page 84)

That is, we compare the set of values assigned to $y$ for each substate in which $x$ is assigned to a different value. If there is variation in these sets, then there is a dependency between $y$ and $x$. Looking at (38), for example, in $G_{1}, y$ does not depend on $x$, since the two sets being compared are the same; in $G_{2}, y$ does depend on $x$, since these two sets are different. 


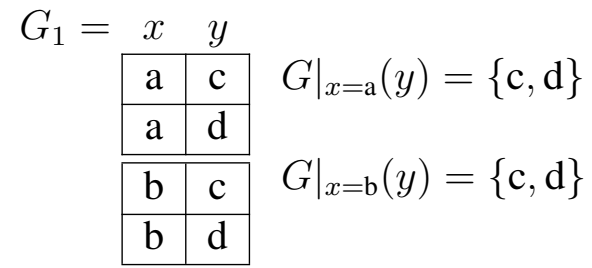

$$
\begin{array}{r}
G_{2}=\begin{array}{ll}
x & y \\
\hline \mathrm{a} & \mathrm{c} \\
\hline \mathrm{a} & \mathrm{d} \\
\hline \mathrm{b} & \mathrm{c} \\
\hline \mathrm{b} & \mathrm{c} \\
\hline \mathrm{b} & \mathrm{e} \\
\hline
\end{array}
\end{array}
$$

\subsection{Making it dynamic}

Having developed a way to talk about the static properties of these representations, we now move to the dynamic components of the model. The basic operation underlying dynamic change is assignment modification, which allows us to add a new discourse referent into a context.

\section{(39) Definition:}

$$
g[x] h \text { iff for any index } i \text {, if } i \neq x \text {, then } g(i)=h(i)
$$

For two assignment functions $g, h$, if $g[x] h$, then $h$ is identical to $g$ except at $x$. For example, (40) provides possible values for $g$ and $h$ if $g[z] h$ is true.

(40) Possible values for $g, h$ if $g[z] h$ :
a. $g=$\begin{tabular}{r|r|r|}
\hline & $y$ & $z$ \\
\hline $\mathbf{a}$ & $\mathbf{b}$ & $\mathbf{c}$ \\
\hline
\end{tabular}
b. $h=$\begin{tabular}{|l|l|l|}
$x$ & $y$ & $z$ \\
\hline $\mathrm{a}$ & $\mathrm{b}$ & $\mathrm{d}$ \\
\hline
\end{tabular}

Following Brasoveanu (2008, 2013) and Henderson (2014), a plural is introduced into an information state by distributing the atoms of the plural across the cells of the column of a new index, keeping all other assignments the same. ${ }^{6}$

\section{Definition: \\ $G[x] H=\mathbb{T} \quad$ iff $\quad$ for all $g \in G$, there is a $h \in H$ such that $g[x] h$, and for all $h \in H$, there is a $g \in G$ such that $g[x] h$}

Let us see how this works with the $G$ and $H$ in (42). To check that $G[y] H$, we first check that for each $g$ there is an $h$ such that $g[y] h$; this holds: $g_{1}[y] h_{1}$ and $g_{2}[y] h_{2}$. Conversely, we check that for each $h$ there is an $g$ such that $g[y] h$; this also holds: $g_{1}[y] h_{1}, g_{2}[y] h_{2}$, and $g_{2}[y] h_{3}$. Therefore, $G[y] H$ holds of this input and output state.
a. $G=$

\begin{tabular}{l|c|c|}
\multicolumn{1}{c}{} & \multicolumn{1}{c}{$x$} & $y$ \\
\cline { 2 - 3 }$g_{1}$ & $\mathrm{a}$ & $\diamond$ \\
\cline { 2 - 3 }$g_{2}$ & $\mathbf{b}$ & $\star$ \\
\cline { 2 - 3 } & &
\end{tabular}
b. $H=$

\begin{tabular}{c|c|c|}
\multicolumn{1}{c}{} & \multicolumn{1}{c}{$x$} & $y$ \\
\cline { 2 - 3 }$h_{1}$ & $\mathrm{a}$ & $\mathrm{c}$ \\
\cline { 2 - 3 }$h_{2}$ & $\mathrm{~b}$ & $\mathrm{~d}$ \\
\cline { 2 - 3 }$h_{3}$ & $\mathrm{~b}$ & $\mathrm{e}$ \\
& &
\end{tabular}

\footnotetext{
${ }^{6}$ Note that the definition of plural introduction is different from van den Berg 1996 and Nouwen 2003; for discussion, see Brasoveanu 2008 and Kuhn 2015
} 
One thing of note that this example illustrates is that $G$ and $H$ may differ in cardinality, since some $g \in G$ may correspond to multiple $h_{1}, \ldots, h_{n} \in H$, provided that $h_{1}, \ldots, h_{n}$ differ only with respect to the newly assigned index.

We define $[x]$ to be index introduction relativized to an input and output state, as in (43).

$$
[x] \quad:=\lambda G H \cdot G[x] H
$$

A dynamic predicate $P$ is a test that ensures that a certain property holds between the values of $n$ indices on each assignment function in an information state. An interpretation function $I$ associates a given dynamic predicate $P$ with a relation on individuals that characterizes the meaning of the predicate. For a given input state $G$, the $n$-ary dynamic predicate $P$ checks that $I(P)$ holds of the values of a certain $n$ indices for each $g \in G$. Following convention in recent works, I use SMALL CAPS to indicate the meaning of a predicate in PCDRT.

$$
\begin{aligned}
& \text { Definition: } \\
& P\left(x_{1}, \ldots, x_{n}\right) \quad:=\quad \lambda G H . G=H \quad \& \forall g \in G \cdot\left\langle g\left(x_{1}\right), \ldots, g\left(x_{n}\right)\right\rangle \in I(P)
\end{aligned}
$$

For example, the classical relation $I$ (INVITED) is the set of 2-tuples $\langle d, e\rangle$ such that $d$ invited $e$. The dynamic proposition $\operatorname{IN} \operatorname{vited}(x, y)$ would hold of the representation in (42b) if $I$ (INVITED) contains $\langle\mathrm{a}, \mathrm{c}\rangle,\langle\mathrm{b}, \mathrm{d}\rangle$, and $\langle\mathrm{b}, \mathrm{e}\rangle$ - that is, if a invited $\mathrm{d}, \mathrm{b}$ invited $\mathrm{d}$, and $\mathrm{b}$ invited e. Note that this preserves the internal structure of the information state, and captures cumulative readings automatically.

Conjunction is interpreted dynamically, as defined in (45), so that operators in the right conjunct have access to discourse referents introduced in the left conjunct, but not vice versa.

$$
\varphi \wedge \psi \quad:=\quad \lambda G H . \exists K . \varphi(G)(K) \& \psi(K)(H)
$$

Dynamic conjunction entails that some information state $(K)$ is the output state of the left conjunct and the input state of the right conjunct; as a result, we can illustrate conjunction as a sequence of states: (46a) holds if there is a $K$ such that (46b) holds.
a. $G \stackrel{\varphi \wedge \psi}{\longrightarrow} H$
b. $G \stackrel{\varphi}{\longrightarrow} K \stackrel{\psi}{\longrightarrow} H$

The logical form in (47) provides an example in which $[x]$ is conjoined with the predicate $\operatorname{GIRLS}(x)$. Figure 4 illustrates these operations graphically. In Figure 4 (and subsequent figures), a double-right arrow $(\Rightarrow$ ) represents the dynamic contribution of a given proposition; the proposition in question is indicated as a superscript above the arrow. As we have seen, a proposition $\varphi$ defines a two-place relation on information states. In the figure below, each arrow relates a set of input states to a set of output states: the set of states to the right of an arrow ' $\Longrightarrow$ ' are the complete set of states $H$ that have a state $G$ to the left of the arrow such that $\varphi(G)(H)$. We illustrate conjunction as the sequence of sets of states connected by arrows.

We model a 'neutral context' as a singleton set containing an empty information state. Figure 4 illustrates (47) evaluated in a neutral context: first, a plurality is introduced across the 
index $x$; then the predicate GIRLS $(x)$ filters out the information states in which $x$ does not consist of girls. (Note that the figures below only show a partial representation, since a proposition may generate a potentially infinite number of output states.)

$$
[x] \wedge \operatorname{GiRLS}(x)
$$

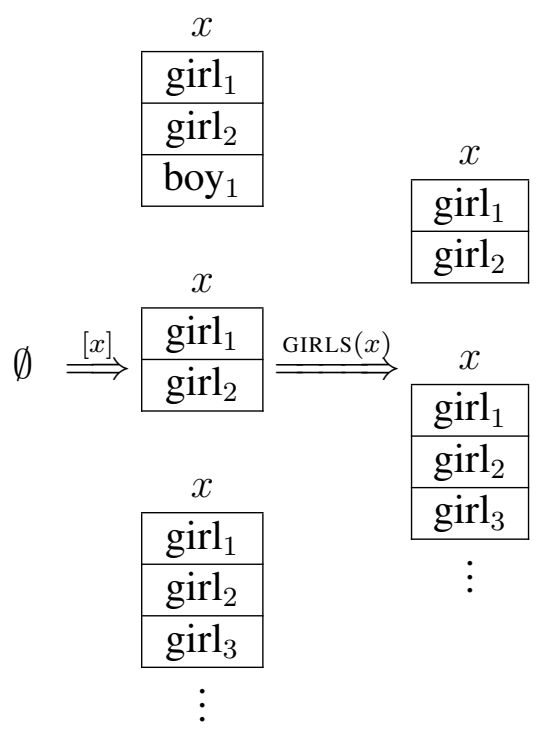

Figure 4: Partial representation of dynamic updates of (47)

The distributive operator is defined in (48). As we saw in $\S 4.1$, in natural language, existential expressions in the scope of a distributive operator are able to introduce new discourse referents into the context-relevant examples included discourses like 'Two farmers each own a donkey. Neither of them treat it very well.' Nevertheless, there must be some constraints that prevent the information state from changing in pathological ways. In (48a), the condition that $G(x)=H(x)$ ensures that the values of the index being distributed over- $x$-remain constant from the input to the output (this is not to be confused with the condition elsewhere that $G=H$, which requires full identity of $G$ and $H$ ).

The meat of the definition-the dynamic component-appears in (48b). Given an inputoutput pair $\langle G, H\rangle, \delta_{x}(\varphi)$ considers the substates of $G$ and $H$ with $x$ restricted to each value $d$. For each of these pairs of substates, the clause in (48b) states that the output substate can be attained from the input substate via the evaluation of $\varphi$. If the evaluation of $\varphi$ introduces a new discourse referent into the context, this means that a discourse referent is introduced in $H$ for each value of $x$.

(48) Definition:

$$
\begin{aligned}
\delta_{x}(\varphi):=\quad & \lambda G H . \\
& G(x)=H(x) \& \\
& \forall d \in G(x) \cdot \varphi\left(\left.G\right|_{x=d}\right)\left(\left.H\right|_{x=d}\right)
\end{aligned}
$$


Procedurally, because the sub-computations of $\varphi\left(\left.G\right|_{x=d}\right)\left(\left.H\right|_{x=d}\right)$ are independent from each other, the evaluation of $\delta_{x}$ can be thought of as a process of dividing up $G$ with respect to the values of $x$, evaluating $\varphi$ on each of these substates in parallel, then gathering up the resulting states. The logical form in (49) provides an example to illustrate this procedural metaphor. As seen in Figure 5, $\delta_{x}$ splits the computation along the $x$ index, adds one book that was read by $x$ as a value for $y$, then merges the computation together again.

$$
\delta_{x}([y] \wedge \operatorname{BOOK}(y) \wedge \operatorname{READ}(y, x))
$$

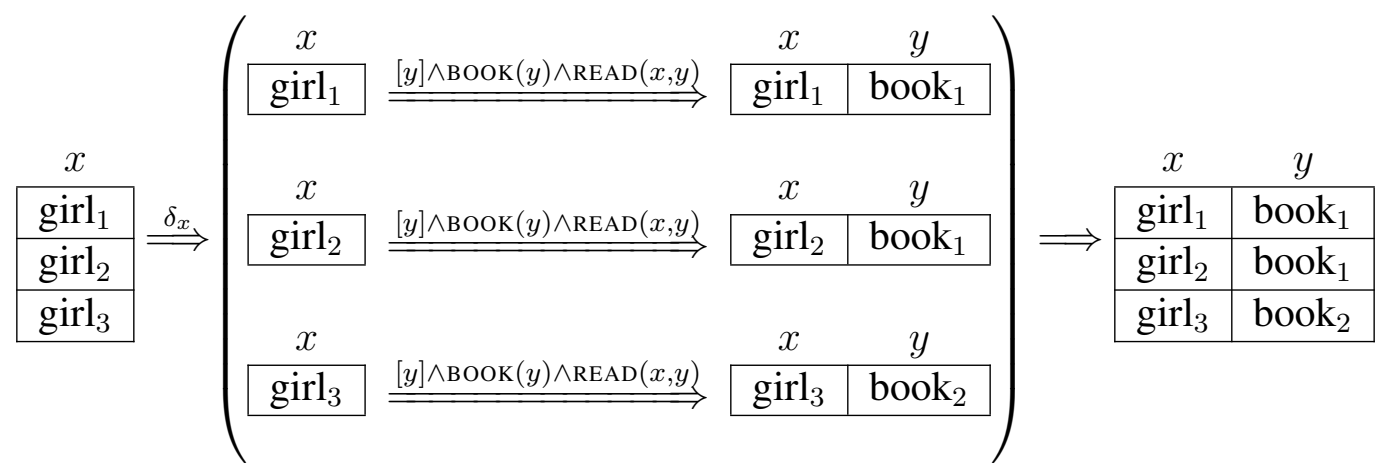

Figure 5: Partial representation of dynamic updates in (49)

To give a concrete example, we will assume (50b) to be the meaning of the natural language sentence in (50a); here, some is associated with the logical expression $[x]$, each is associated with the expression $\delta_{x}$, and $a$ is associated with $[y]$. Because (50b) is the conjunction of (47) and (49), a graphical representation for (50b) can be created by composing Figure 4 with Figure 5. Figure 6 shows the results of this composition.

a. Some girls each read a book.

b. $[x] \wedge \operatorname{GiRLS}(x) \wedge \delta_{x}([y] \wedge \operatorname{BOOK}(y) \wedge \operatorname{READ}(x, y))$

\begin{tabular}{|c|c|}
\multicolumn{1}{c}{$x$} & $y$ \\
\hline girl $_{1}$ & book $_{1}$ \\
\hline girl $_{2}$ & book $_{1}$ \\
\hline
\end{tabular}

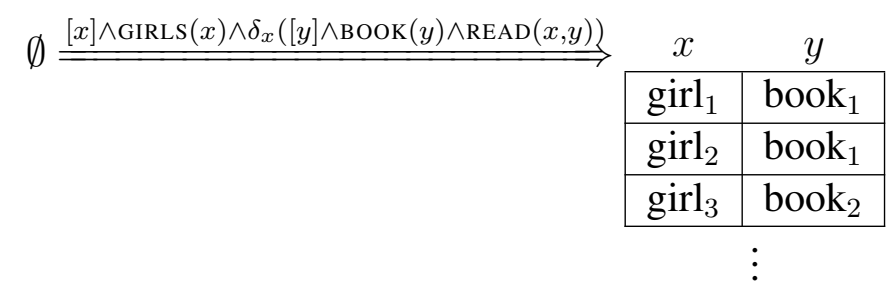

Figure 6: Partial representation of the dynamic updates of (50) 
Observe that the output states in Figure 6 have a dependency in the formal sense defined in (37): the values of $y$ depend on the values of $x$.

In order to define the determiner each (as in 'each boy'), we will also need a maximality operator that ensures that every single individual in the restrictor is considered by the distributive operator. This will not interact in any particularly interesting way in the system that we have built, but is included for completeness. We adapt the definition for max from Brasoveanu 2013.

$$
\begin{aligned}
& \max _{i}(\varphi):= \\
& \lambda G H .([x] \wedge \varphi)(G)(H) \& \neg \exists H^{\prime} \cdot H(x) \subset H^{\prime}(x) \&([x] \wedge \varphi)(G)\left(H^{\prime}\right)
\end{aligned}
$$

Cardinality measures are also tests. Adapting Brasoveanu 2013, we define the dynamic proposition 'inside $(x)=n$ ' as in (52) $)^{7}$. For an input information state $G$ and an integer $n$, 'inside $(x)=n$ ' tests that there are exactly $n$ distinct values of $g(x)$ for $g \in G$.

$$
\operatorname{inside}(x)=n \quad:=\quad \lambda G H \cdot G=H \quad \&|H(x)|=n
$$

For example, in (42b), $|H(x)|=2$ and $|H(y)|=3$.

The following example illustrates the behavior of index introduction and predication in Brasoveanu 2013's system with a simple sentence. The meaning of (53a) is provided in (53b), and is illustrated in (54). Since conjunction is interpreted dynamically, the logical form in (53b) is read from left to right. First, $[x]$ introduces some plurality of individuals for the index $x$, with no restrictions on their value. The resulting set of output states are filtered to only include those where the cells of $x$ are girls, then filtered again so that there are only two values in the cells of $x$.

In the next block, $[y]$ introduces the index $y$; observe that either column in the $x$ or $y$ can have duplicate values, as we observed in (42). The two tests then filter the $y$ column to only include dogs, then to have only three values. Finally, the relation SAW filters out only those information states in which each value of $x$ saw the value of $y$ in the same row.

A sentence is evaluated as true with respect to a given input context if there are any output contexts after evaluation of the sentence.

a. Two ${ }^{x}$ girls saw three ${ }^{y}$ dogs.

b. $[x] \wedge \operatorname{GiRLS}(x) \wedge x=2 \wedge[y] \wedge \operatorname{DOGS}(y) \wedge y=3 \wedge \operatorname{SAW}(x, y)$

\footnotetext{
${ }^{7}$ Brasoveanu 2013 defines this with the perhaps slightly more intuitive notation ' $|x|=n$.' I have changed this notation in anticipation of notions of 'inside' and 'outside' plurality that will be defined in $\S 5.1$.
} 


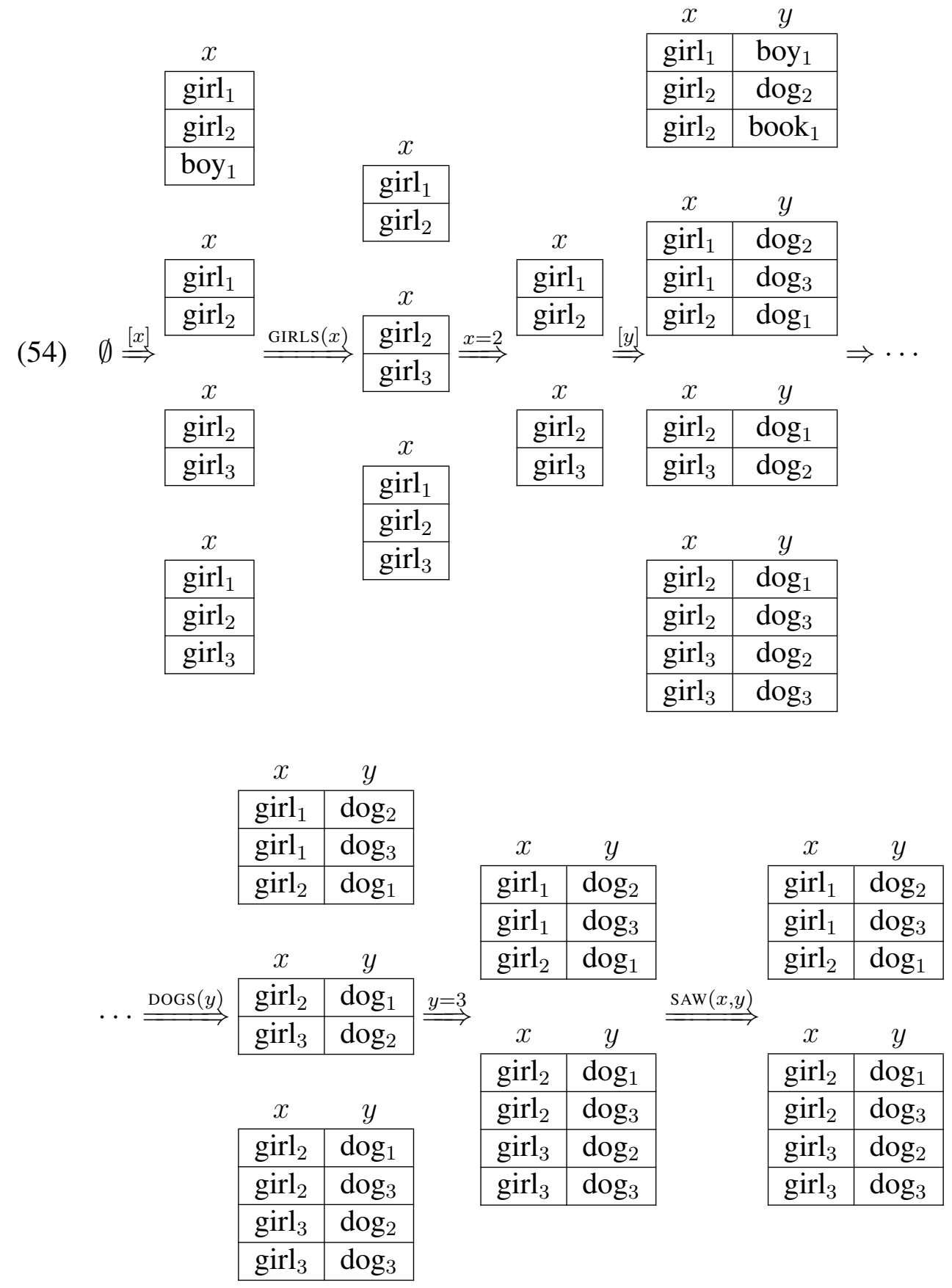

\section{Proposal for dependent indefinites}

\subsection{Dependent indefinites in PCDRT}

In $\S 3.5$, I proposed that dependent indefinites introduce a plurality into discourse, and consist of two components of meaning, repeated in (55). 
(55) a. Presupposition: the plurality can be divided into subpluralities that vary with respect to the atoms of a licensor.

b. At-issue: each of these subpluralities is of a given cardinality.

We are now in a position to translate this proposal into Plural Compositional DRT.

We consider an information state, divided up with respect to the values of the licensor. Suppose that $y$ is the index introduced by a dependent indefinite and $x$ is the index introduced by its licensor. Recall from the definitions in (34) and (35) that $G_{x=d}(y)$ is the set of values that $y$ takes on those assignment functions that map $x$ to $d$. Collecting each set that we get as we let $d$ range over the values of $x$ provides us a way to divide up the value of $y$ into a set of sets. This set of sets is formally defined in (56) for a given $G$.

$$
\left\{S: \exists d\left(\left.d \in G(x) \& G\right|_{x=d}(y)=S\right)\right\}
$$

As an example, consider the information state in (58a), perhaps generated by evaluation of a sentence with a dependent indefinite. Here, $x$ corresponds to the licensor; $y$ corresponds to the dependent indefinite. The set of sets in (58b) provides a cover of the elements of $G(y)$.

(57) Every ${ }^{x}$ boy saw two-two ${ }^{y}$ girls.

$$
\text { a. } G=x y
$$

\begin{tabular}{|c|c|}
\hline $\mathrm{a}$ & $\mathrm{d}$ \\
\hline $\mathrm{a}$ & $\mathrm{e}$ \\
\hline $\mathrm{b}$ & $\mathrm{f}$ \\
\hline $\mathrm{b}$ & $\mathrm{g}$ \\
\hline $\mathrm{c}$ & $\mathrm{h}$ \\
\hline $\mathrm{c}$ & $\mathrm{i}$ \\
\hline
\end{tabular}

b. $\left\{S: \exists d\left(\left.d \in G(x) \& G\right|_{x=d}(y)=S\right)\right\}=\{\{\mathrm{d}, \mathrm{e}\},\{\mathrm{f}, \mathrm{g}\},\{\mathrm{h}, \mathrm{i}\}\}$

The presupposition and at-issue component in (55) can now be formalized with reference to this set of sets. The presupposition in (55a) can be stated as in (59). This 'outside' cardinality measurement checks that the set of sets itself has a certain cardinality.

$$
\begin{aligned}
& \operatorname{outside}(y / x)>1 \\
& \quad:=\quad \lambda G H . G=H \quad \& \quad\left|\left\{S: \exists d\left(\left.d \in H(x) \& H\right|_{x=d}(y)=S\right)\right\}\right|>1
\end{aligned}
$$

Note that the predicate 'outside $(y / x)>1$ ' is a dynamic test that checks that $y$ is dependent on $x$, in the formal sense of Nouwen 2003, defined in (37) and repeated in (60).

(60) In an information state $G, y$ is dependent on $x$ iff

$$
\exists d,\left.e \in G(x) \cdot G\right|_{x=d}(y) \neq\left. G\right|_{x=e}(y)
$$

The at-issue component in (55b) can be stated as in (61). This 'inside' cardinality measurement checks that each member of the set of sets has a certain cardinality. 


$$
\begin{aligned}
& \operatorname{inside}(y / x)=n \\
& \quad:=\quad \lambda G H . G=H \quad \& \quad \forall T \in\left\{S: \exists d\left(\left.d \in H(x) \& H\right|_{x=d}(y)=S\right)\right\} \cdot|T|=n
\end{aligned}
$$

Thus, the information state in (58a) satisfies 'outside $(y / x)>1$ ' because there is more than one element in the set in (58b) - it contains three sets. It satisfies 'inside $(y / x)=2$ ' because each of these three sets contains two individuals.

It may be useful to observe how our starting two architectural questions are manifested in these definitions. First, the fact that the definitions are anaphoric can be seen in the fact that both (59) and (61) make direct reference to the index $x$, introduced by the licensor of the dependent indefinite. Second, the fact that the at-issue component is inherently quantificational can be seen in the universal quantification, ' $\forall T$,' that appears in (61).

\subsection{Fragment}

We are now able to provide a full fragment with lexical definitions. I will begin by collecting all the definitions and notational short-hand that were defined in the previous section. The table in Figure 7 provide the types of various important components of the system. Sentences denote propositions, functions that take two information states (an input and and output) and return a

\begin{tabular}{|c|c|c|c|c|}
\hline Type & & Variables & \multicolumn{2}{|c|}{ Example } \\
\hline \multicolumn{2}{|l|}{ truth value } & & \multicolumn{2}{|c|}{ true, false } \\
\hline & $i, j, k, l$ & \multicolumn{2}{|c|}{$w, x, y, z$} \\
\hline entity & & & \multicolumn{2}{|c|}{ john, mary } \\
\hline \multicolumn{2}{|l|}{ integers } & $n, m$ & \multicolumn{2}{|c|}{1,2} \\
\hline predicate & index $\rightarrow$ proposition & $P, Q, N$ & \multicolumn{2}{|c|}{ LEFT, ZEBRA } \\
\hline \multirow{2}{*}{ assignment function } & \multirow{2}{*}{ index $\rightarrow$ entity } & \multirow{2}{*}{$g, h$} & $x$ & $y$ \\
\hline & & & al & eve \\
\hline \multirow{3}{*}{ information state } & \multirow{3}{*}{ assign. fn. $\rightarrow$ truth value } & \multirow{3}{*}{$G, H$} & $x$ & $y$ \\
\hline & & & al & eve \\
\hline & & & ed & ann \\
\hline proposition & inf. state $\rightarrow$ inf. state $\rightarrow$ truth value & $\varphi, \psi$ & & \\
\hline
\end{tabular}
truth value. The definitions in (62)-(73) provide the full system developed above.

Figure 7: List of types for fragment

(63) $\left.G\right|_{i=d}:=\{g \mid g \in G \& g(i)=d\}$

(64) $g[i] h \Leftrightarrow$ for any index $j$, if $j \neq i$, then $g(j)=h(j)$

(65) $G[i] H \quad \Leftrightarrow \quad$ for all $g \in G$, there is a $h \in H$ such that $g[i] h$, and for all $h \in H$, there is a $g \in G$ such that $g[i] h$ 


$$
\begin{aligned}
& {[j]:=\quad \lambda G H . G[j] H} \\
& \varphi \wedge \psi:=\quad \lambda G H . \exists K \cdot \varphi(G)(K) \& \psi(K)(H)
\end{aligned}
$$

(68) For any $n$-place predicate $P$ with classical logic denotation $I(P)$,

$$
\begin{aligned}
& P\left(i_{1}, \ldots, i_{n}\right) \quad:=\lambda G H . G=H \quad \& \forall g \in G \cdot\left\langle g\left(i_{1}\right), \ldots, g\left(i_{n}\right)\right\rangle \in I(P) \\
& \delta_{i}(\varphi) \quad:=\lambda G H \cdot G(i)=H(i) \& \forall d \in G(i) \cdot \varphi\left(\left.G\right|_{i=d}\right)\left(\left.H\right|_{i=d}\right) \\
& \max _{i}(\varphi) \quad:=\lambda G H .([x] \wedge \varphi)(G)(H) \& \neg \exists H^{\prime} . H(x) \subset H^{\prime}(x) \&([x] \wedge \varphi)(G)\left(H^{\prime}\right) \\
& \operatorname{inside}(j)=n \quad:=\quad \lambda G H . G=H \&|H(j)|=n \\
& \operatorname{inside}(j / i)=n \\
& :=\lambda G H . G=H \& \forall T \in\left\{S: \exists d\left(\left.d \in H(i) \& H\right|_{i=d}(j)=S\right)\right\} .|T|=n \\
& \text { outside }(j / i)>1 \\
& :=\lambda G H . G=H \&\left|\left\{S: \exists d\left(\left.d \in H(i) \& H\right|_{i=d}(j)=S\right)\right\}\right|>1
\end{aligned}
$$

We are now in a position to provide lexical definitions. Following are the predicates that I will use in derivations.
a. $\llbracket$ students $\rrbracket=\lambda j \cdot \operatorname{STUDENTS}(j)$
b. $\llbracket z e b r a s \rrbracket=\lambda j \cdot \operatorname{ZEBRAS}(j)$
c. $\llbracket$ left $\rrbracket=\lambda j \cdot \operatorname{LEFT}(j)$
d. $\llbracket \mathrm{saw} \rrbracket=\lambda i j . \operatorname{SAw}(i)(j)$

Note that the output to all these functions is a propositional type-i.e. a function from a pair of information states to a truth value. I have just 'hidden' the information states in these

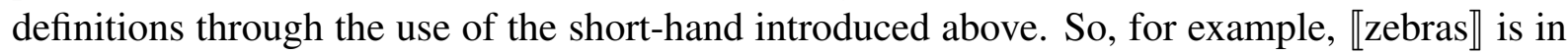
fact a function that takes an index $(j)$, then two information states $(G$ and $H)$, then returns a truth value.

A plain numeral is given a meaning as in (75). A plain numeral built from the integer $n$ introduces an index $j$, checks that $j$ satisfies the predicates of its two complements, then checks that there are exactly $n$ distinct values in $G(j)$.

$$
\llbracket \text { three }^{j} \rrbracket=\lambda N P \cdot[j] \wedge N(j) \wedge P(j) \wedge \operatorname{inside}(j)=3
$$

A dependent numeral is given a meaning as in (76). Here, I use the pseudo-English two-two to stand in for a dependent indefinite like we see in Telugu, Kaqchikel, and so on. A dependent numeral built from $n$ and anaphoric to an index $i$ introduces an index $j$, checks that $j$ satisfies the predicates of its two complements, checks that there are at least two distinct sets in the value of $G(j)$ restricted by $i$, then checks that each of these sets has cardinality $n$.

$$
\llbracket \operatorname{two}^{-t_{w o}}{ }_{i}^{j} \rrbracket=\lambda N P \cdot[j] \wedge N(j) \wedge P(j) \wedge \operatorname{outside}(j / i)>1 \wedge \operatorname{inside}(j / i)=2
$$

One thing that is important to note about the definition in (76) is the order in which these conditions are evaluated. In particular, the two cardinality checkers are evaluated after the two predicates are introduced. What this means is that the cardinality checkers may be dependent on 
an index that is introduced by a complement of the dependent indefinite. This is the reflection in my analysis of Henderson 2014's insight that the plurality condition of a dependent numeral is somehow 'postsuppositional' (see discussion in $\$ 6$ ). However, my system does not encode this through an enrichment to the architecture, but instead as a property of a lexical definition.

Finally, we define each, as follows. Each introduces an index $i$, checks that this index contains the maximum set of individuals in its restrictor $N$, evaluates the proposition that the predicate $P$ holds of $i$ for each value of $i$, then returns the union of the output states.

$$
\llbracket \operatorname{each}^{i} \rrbracket=\lambda N P \cdot \mathbf{m a x}_{i}(N(i)) \wedge \delta_{i}(P(i))
$$

I assume that quantifiers can move by Quantifier Raising (QR) as in standard analyses of scope. Notationally, I use the following convention for QR: given a logical form matching the schema in (78a), I assume that you can derive a logical form matching the schema in (78b).

a.

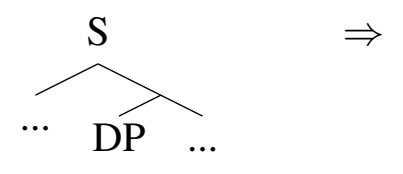

b.

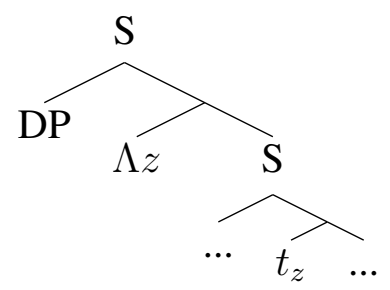

\subsection{Examples}

In this section, I work through several derivations to show how the system works. I include one derivation of a sentence without a dependent indefinite, one sentence with a dependent indefinite licensed by a plural (without a distributivity operator), and one derivation of a dependent indefinite licensed by a distributive operator. Like the definitions above, the sentences I am deriving are not any specific language, but are taken to stand in for the licensing patterns and interpretations that were described cross-linguistically in examples (12)-(16).

Example (79a) provides a sentence without a dependent indefinite. The derivation for the logical form in (79b) is shown in (80). Working step by step through the logical form, the sentence says the following: given an input state $G,[x]$ introduces a plurality of individuals across the cells of a column (the index $x$ ); $\operatorname{STUDENTS}(x)$ is a test that checks that each cell in $x$ is a student; $\operatorname{LEFT}(x)$ checks that each cell in $x$ left; inside $(x)=3$ checks that there are three distinct values in the cells of $x$. The sentence is true of any output states $H$ - that is, any states where there are three students who left.

(84) provides some possible output contexts for the sentence evaluated in a neutral context.

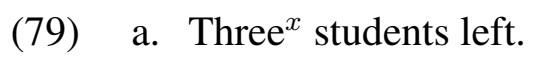

b. $[x] \wedge \operatorname{Students}(x) \wedge \operatorname{LEFT}(x) \wedge$ inside $(x)=3$ 


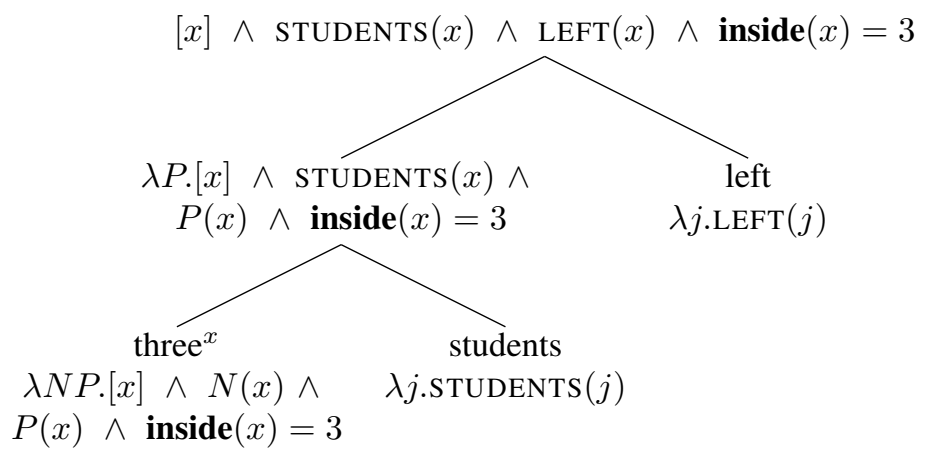

$(81)$

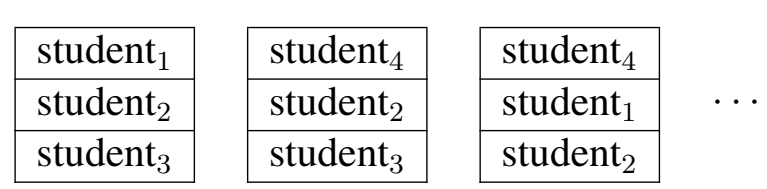

Example (82a) provides a sentence with a dependent indefinite licensed by the plural three students. The derivation for the logical form in (82b) is shown in (83). Working step by step through the logical form, the sentence says the following: given an input state $G,[x]$ introduces a plurality of individuals across the cells of index $x$; $\operatorname{STUDENTS}(x)$ is a test that checks that each cell in $x$ is a student; $[y]$ introduces a plurality of individuals across the cells of index $y$; $\operatorname{ZEBRAS}(y)$ is a test that checks that each cell in $y$ is a zebra; $\operatorname{SAW}(y)(x)$ checks that the value of $x$ in each row saw the value of $y$ in that row; inside $(x)=3$ checks that there are three distinct values in the cells of $x$; outside $(y / x)>1$ checks that the values of $y$ depend on the values of $x$; $\operatorname{inside}(y / x)=2$ checks that there are two distinct values of $y$ for each value of $x$. The sentence is true of any output states $H$-that is, any states where there are three students who saw zebras, they didn't all see the same zebras, and there are two zebras per student.

(84) provides some possible output contexts for the sentence evaluated in a neutral context.

a. Three ${ }^{x}$ students saw two-two ${ }_{x}^{y}$ zebras.

b. $[x] \wedge \operatorname{StUdents}(x) \wedge[y] \wedge \operatorname{ZeBras}(y) \wedge \operatorname{SaW}(y)(x) \wedge$ $\operatorname{inside}(x)=3 \wedge \operatorname{outside}(y / x)>1 \wedge \operatorname{inside}(y / x)=2$ 


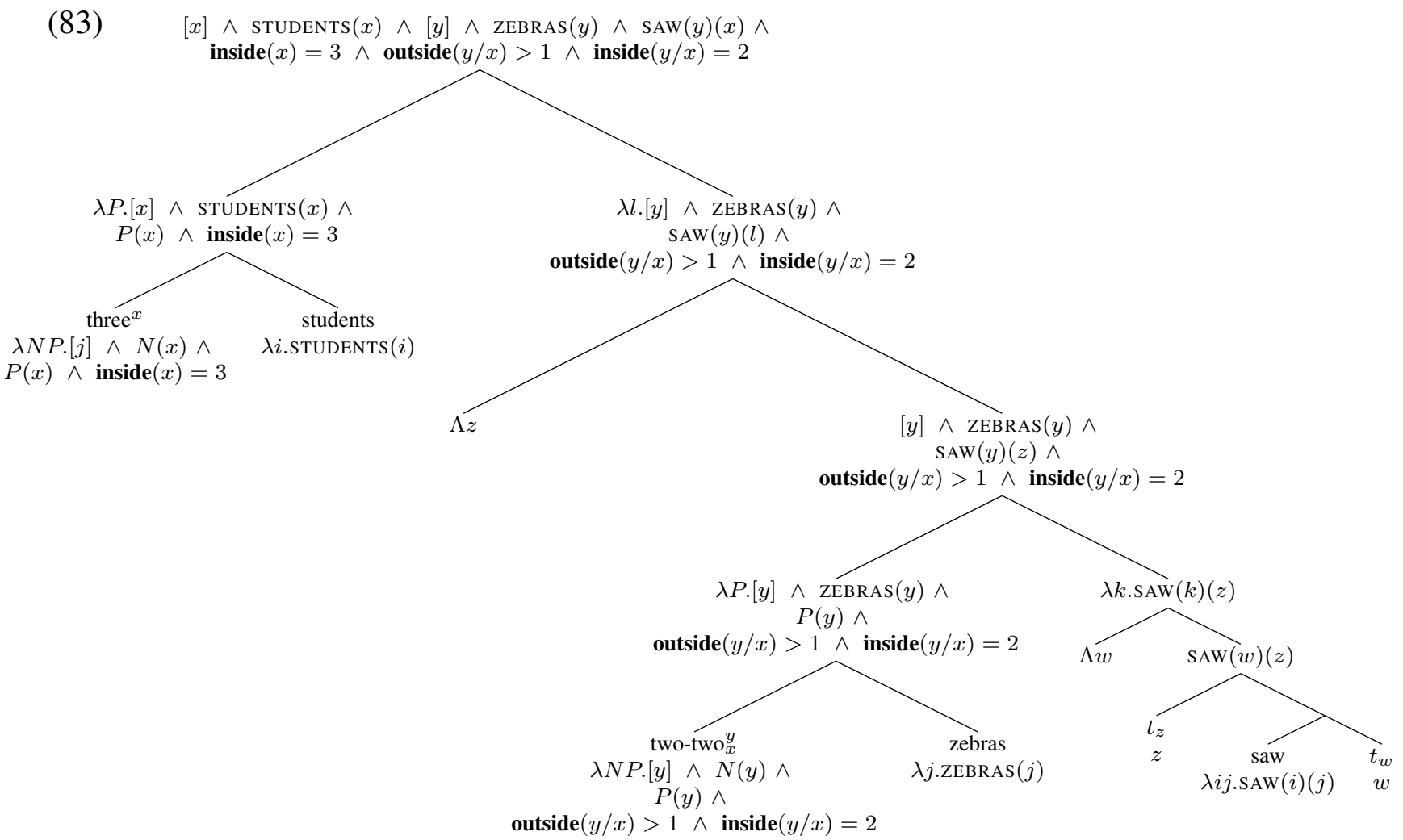

(84)

\begin{tabular}{|l|l|}
\hline student $_{1}$ & zebra $_{1}$ \\
\hline student $_{1}$ & zebra $_{2}$ \\
\hline student $_{2}$ & zebra $_{1}$ \\
\hline student $_{2}$ & zebra $_{2}$ \\
\hline student $_{3}$ & zebra $_{1}$ \\
\hline student $_{3}$ & zebra $_{3}$ \\
\hline
\end{tabular}$\quad$\begin{tabular}{|l|l|}
\hline student $_{1}$ & Zebra $_{1}$ \\
\hline student $_{1}$ & Zebra $_{2}$ \\
\hline student $_{2}$ & Zebra $_{3}$ \\
\hline student $_{2}$ & Zebra $_{4}$ \\
\hline student $_{3}$ & Zebra $_{5}$ \\
\hline student $_{3}$ & Zebra $_{6}$ \\
\hline
\end{tabular}

Finally, we consider licensing by a distributive operator, as in the sentence in (85a). First, we consider a derivation that fails. In the tree in (86), the distributive operator each scopes outside the dependent indefinite $t w o-t w o$. The result of this is that the variation condition-i.e., the condition that outside $(y / x)>1$-appears inside the distributive scope of $\delta_{x}$, so is evaluated with respect to a substate of $G$ where $x$ is restricted to a single value. The variation condition needs at least two values of $x$ to compare, so the variation condition cannot be met, and the derivation fails.

(85) a. $\operatorname{Each}^{x}$ student saw two-two ${ }_{x}^{y}$ zebras.

b. $\max _{x}(\operatorname{STUdent}(x)) \wedge$

$$
\delta_{x}([y] \wedge \operatorname{ZEBRAS}(y) \wedge \operatorname{SAW}(y)(x) \wedge \operatorname{outside}(y / x)>1 \wedge \operatorname{inside}(y / x)=2)
$$




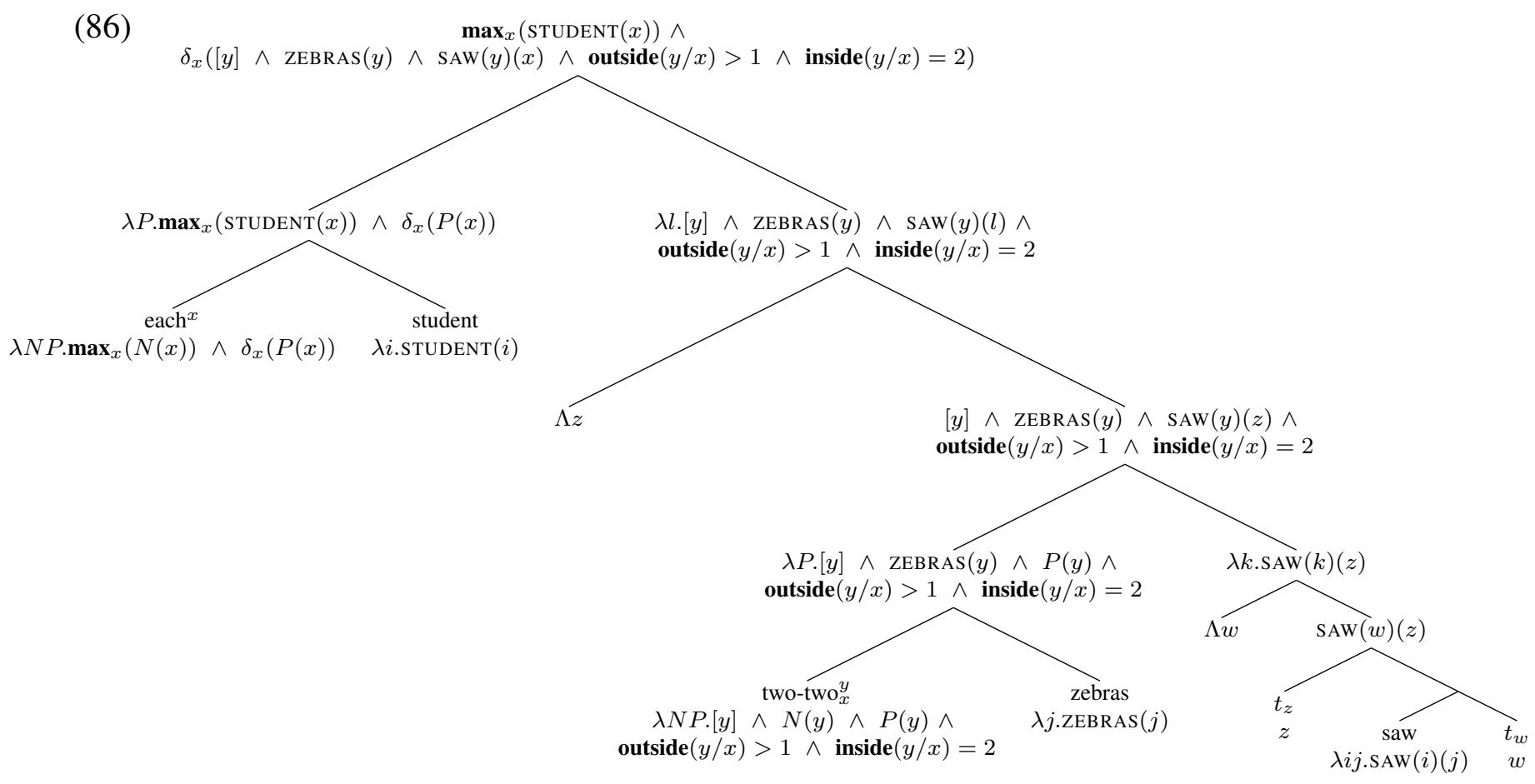

On the other hand, if the dependent indefinite takes scope outside the distributive operator, the derivation succeeds. The tree in (88) derives the logical form in (87b). In (87b), the only expression occurring in the distributive scope of $\delta_{x}$ is the relation $\mathrm{SAW}(y)(x)$; of note, the variation condition that outside $(y / x)>1$ appears after this scope has closed, giving it access to the full set of values of $x$ and $y$.

The logical form says the following: given an input state $G,[y]$ introduces a plurality of individuals across the cells of index $y \operatorname{ZEBRAS}(y)$ is a test that checks that each cell in $y$ is a zebra; $\max _{x}(\operatorname{STUDENT}(x))$ introduces the maximum set of boys across the cells of index $x$; $\delta_{x}(\operatorname{SAW}(y)(x))$ divides the state into substates restricted by the value of $x$, checks that the value of $x$ in each row saw the value of $y$ in that row, then collects the substates again; outside $(y / x)>$ 1 checks that the values of $y$ depend on the values of $x$; inside $(y / x)=2$ checks that there are two distinct values of $y$ for each value of $x$. The sentence is true of any output states $H$ - that is, any states where the maximal set of students saw zebras, they didn't all see the same zebras, and there are two zebras per student.

a. Each $^{x}$ student saw two-two ${ }_{x}^{y}$ zebras.

b. $[y] \wedge \operatorname{ZEBRAS}(y) \wedge \max _{x}(\operatorname{STUdENT}(x)) \wedge$ $\delta_{x}(\operatorname{SAW}(y)(x)) \wedge$

$\operatorname{outside}(y / x)>1 \wedge \operatorname{inside}(y / x)=2$ 


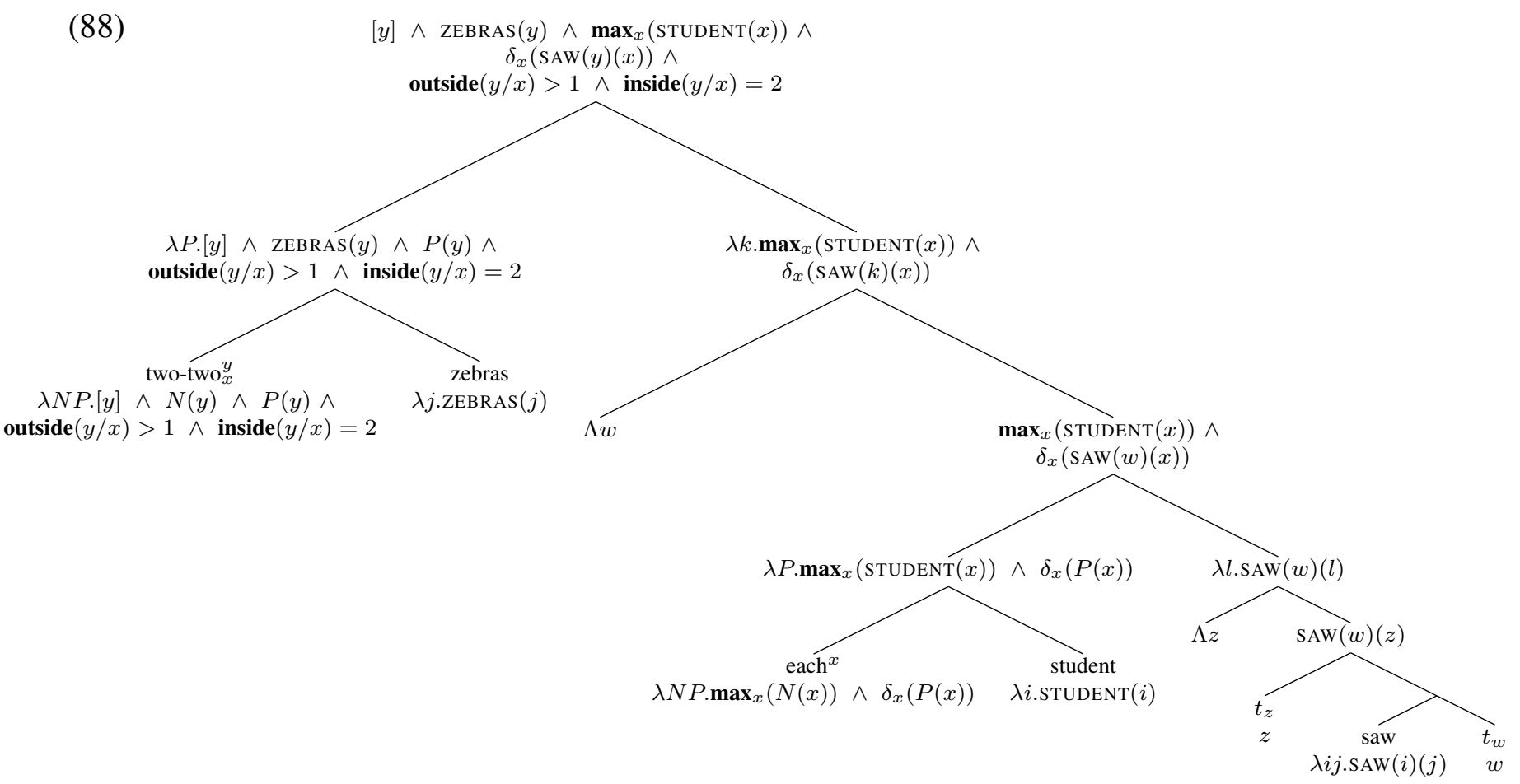

\subsection{Analysis sketch: same}

Turning to same, a parallel analysis can be sketched. As with dependent indefinites, same considers subparts of the plurality introduced by the DP containing same. Dependent indefinites check that of each of these subparts has a certain cardinality; the adjective same checks that each of these subparts are identical to each other.

A number of authors have observed that the adjective same presupposes not a plurality of individuals, but a plurality of events (Carlson 1987, Barker 2007, Hardt et al. 2012, Hardt and Mikkelson 2015). Barker 2007 makes this point for sentences with internal readings of same. He observes that (89) must describe a situation with two separate events; it cannot be used to describe a single event in which John sold Mary a book.

(89) John bought and Mary sold the same book.

(from Barker 2007)

In the fragment that has been developed to this point, I have not included event variables, nor a way to associate an event with its arguments. As the present analysis is already quite complex, I will not do so here.

Nevertheless, without developing an event semantics, the first approximation of an analysis can still be sketched by providing an account for type-identity uses of same. Specifically, we note that the adjective same can be used to describe not only scenarios of token-identity, but also those of type-identity (Nunberg 1984, Lasersohn 2000). For example, the sentence in (90) may be used naturally to describe a situation in which John and Mary read two different copies of the same work of literature-there are multiple book tokens, but a single book type. ${ }^{8}$ 
(90) John and Mary read the same book.

The definitions in (91) and (92) account for the subset of data in which same communicates type-identity. Let $j$ be the index introduced by the DP containing same; let $i$ be the index introduced by a plural licensor. As with dependent indefinites, same considers the set $\left\{\left.H\right|_{i=d}(j)\right\}$ - that is, the sets of values taken by $j$ in the substates where $G$ is restricted by the value of $i$. The adjective same entails that each of these sets are type-identical. I use the notation ' $\equiv$ ' to indicate that two objects are equivalent with respect to type-identity.

Note that the lexical definition of same in (92) includes the variation condition 'outside $(j / i)>$ 1 '. As in the case of dependent indefinites, this condition will ensure that same is licensed by a plural.

$$
\begin{aligned}
& \operatorname{same}(j / i):=\lambda G H . G=H \& \forall S, T \in\left\{\left.H\right|_{i=d}(j)\right\} . S \equiv T \\
& \llbracket \text { the_same }{ }_{i}^{j} \rrbracket=\lambda N P .[j] \wedge N(j) \wedge P(j) \wedge \operatorname{outside}(j / i)>1 \wedge \operatorname{same}(j / i)
\end{aligned}
$$

The following derivations provide two examples of same in action. The tree in (95) provides a derivation for the sentence in (93), where same is licensed by an indefinite plural.

(93) a. Three students read the same book.

b. $[x] \wedge \operatorname{STUdenTS}(x) \wedge[y] \wedge \operatorname{BOOK}(y) \wedge \operatorname{READ}(y)(x) \wedge$ $\operatorname{inside}(x)=3 \wedge \operatorname{outside}(y / x)>1 \wedge \operatorname{same}(y / x)$

The tree in (96) provides a derivation for the sentence in (94), where same is licensed by distributive operator.

(94) a. Each student read the same book.

b. $[y] \wedge \operatorname{BOOK}(y) \wedge \max _{x}(\operatorname{STUdent}(x)) \wedge$

$$
\begin{aligned}
& \delta_{x}(\operatorname{READ}(y)(x)) \wedge \\
& \operatorname{outside}(y / x)>1 \wedge \operatorname{same}(y / x)
\end{aligned}
$$

We note that the variation condition outside $(y / x)>1$ still entails that more than one book was read by the students; the condition same $(y / x)$ entails that these books are type-identical. This seems to correctly capture the truth conditions for type-identity uses of same. To capture token-identity uses of same, outside $(y / x)>1$ would need to be revised to a variation condition on events.

\footnotetext{
${ }^{8}$ In American Sign Language, preliminary investigations with Itamar Kastner suggest that the agreeing form of SAME that is discussed here (with a Y-handshape) is in fact used most felicitously in cases of type-identity-cases of token-identity are preferably signed with non-agreeing SAME or with another translation of 'same' in which the two hands are brought together with the 1-handshape, palms down. However, these seem to be preferences rather than hard constraints.
} 
(95)

$[x] \wedge \operatorname{STUdents}(x) \wedge[y] \wedge \operatorname{BOOK}(y) \wedge \operatorname{READ}(y)(x) \wedge$ $\operatorname{inside}(x)=3 \wedge \operatorname{outside}(y / x)>1 \wedge \operatorname{same}(y / x)$

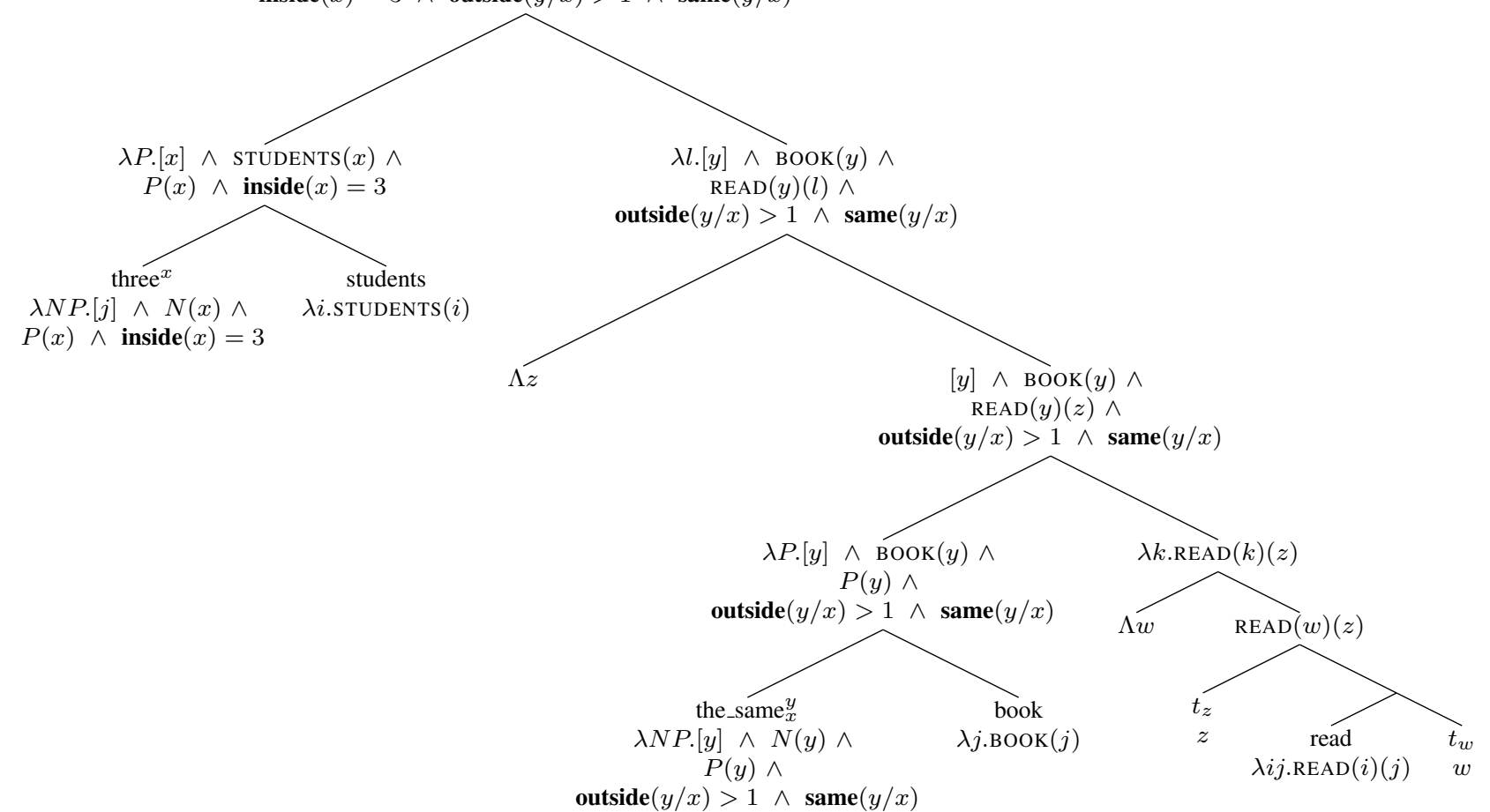

(96)

$[y] \wedge \operatorname{BOoK}(y) \wedge \max _{x}(\operatorname{StUdent}(x)) \wedge$

$$
\delta_{x}(\operatorname{READ}(y)(x)) \wedge
$$

$\operatorname{outside}(y / x)>1 \wedge \operatorname{same}(y / x)$

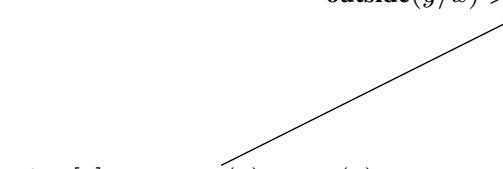

$\lambda P \cdot[y] \wedge \operatorname{BooK}(y) \wedge P(y) \wedge$

$\operatorname{outside}(y / x)>1 \wedge \operatorname{same}(y / x)$
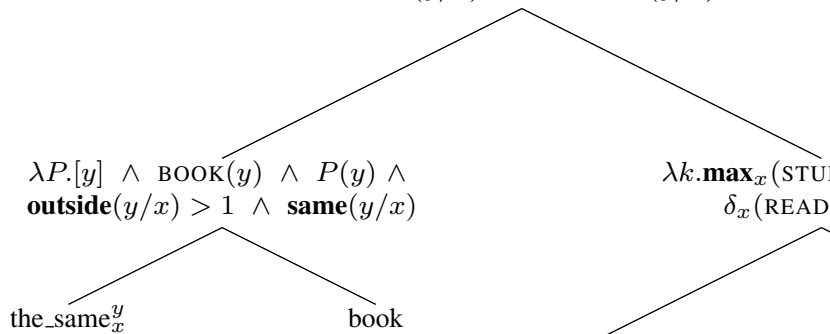

$\lambda N P .[y] \wedge N(y) \wedge P(y) \wedge \quad \lambda j \cdot \operatorname{BoOK}(j)$ $\operatorname{outside}(y / x)>1 \wedge \operatorname{same}(y / x)$

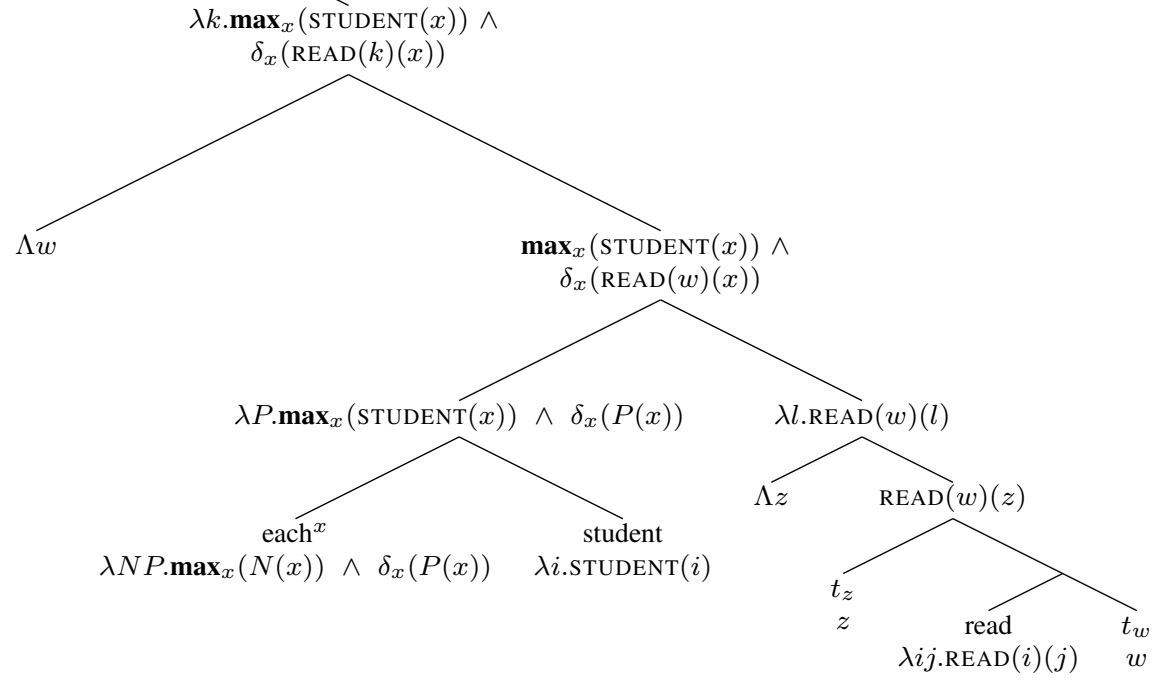




\section{How do dependent indefinites take scope?}

In the proposal above, the essential insights for the licensing of dependent indefinites under distributive operators come from Henderson 2014. To summarize, the mechanism consists of two fundamental parts.

1. The use of Plural Compositional DRT to dynamically track dependency relations.

2. The evaluation of the variation condition after distributive scope has closed.

The statement of the variation condition required reference to the functional associations that are introduced by an indefinite under a distributive operator. PCDRT provided the ability to refer to these functional relations even after the closure of distributive scope.

Although the analysis presented above agrees with Henderson 2014 with respect to this general strategy of scope-taking, the architectural differences between the two proposals (as described in $\S 2$ and $\S 3$ ) have theoretical ramifications for the implementation of this insight. Specifically, on the analysis of Henderson 2014, dependent indefinites have the same at-issue content as plain indefinites - they are not themselves distributive. For Henderson 2014, the result is a kind of 'split-scope': in order to receive a distributive meaning, the at-issue content must scope below the distributive operator; in order to have access to the full plurality, the variation condition must scope above it.

In contrast, the current analysis, with a distributive at-issue component, does not require separation of the two components of meaning - both can take scope over the distributive operator. Thus, standard quantifier raising works, with no need for the mechanisms that Henderson posits to capture the effect of split-scope. In this respect, I view the alternative presented here as a more conservative alternative to Henderson 2014.

On the other hand, an analysis in terms of QR makes specific predictions about the licensing of dependent indefinites by distributive operators, including the behavior of coordinated structures, and dependent indefinites containing bound pronouns. The goal of this section is to evaluate possible mechanisms of scope-taking in light of these these predictions. As we will see, the results are somewhat heterogenous: although English same seems to behave more or less in accordance with the theory developed in $§ 5$, dependent indefinites in Hungarian do appear to show split-scope behavior in certain environments. While this poses challenges for the particular theory developed here, it bears noting that the new data is uncovered only by virtue of comparison to an explicit account that uses more traditional scope-taking. While leaving the ultimate analysis of these puzzles generally open, we observe connections to other recent work on split-scope phenomena (Bumford 2016).

\subsection{Split-scope via postsuppositions}

Henderson delays evaluation of the plurality condition via a mechanism of 'postsuppositions' (Brasoveanu 2012). In classical semantics, presuppositions are a device for accounting for trivalent truth conditions-modeling undefinedness as well as truth and falsity. In a dynamic 
framework, where meaning is represented as a function from an input context to an output context, presuppositions can be formalized as a condition that must hold of an input context in order for a formula to be defined. For example, if $\varphi$ presupposes $\psi$, then $\varphi(G)(H)$ is only defined if $\psi$ is satisfied by the input context $G$. By analogy, a postsupposition is a condition that must hold of an output context in order for a formula to be defined. For example, if $\varphi$ postsupposes $\psi$, then $\varphi(G)(H)$ is only defined if $\psi$ is satisfied by the output context $H$.

In practice, what this means is the following: if the formula doesn't change the context in the relevant way, then the postsupposition essentially behaves like a presupposition; however, because the postsupposition is evaluated after the formula, the formula itself may change the context in such a way to satisfy the postsupposition. The situation can be understood by means of a general paraphrase with a postponed conjunct: if Op is an operator that triggers the evaluation of postsuppositions, then an expression in which a postsupposition $\psi$ appears in the scope of Op is equivalent to an expression in which $\psi$ appears as a conjunct attached after Op has been evaluated, as in (97). (Following Henderson 2014, an overline indicates a postsupposition.)

$$
\mathrm{Op}(A \wedge \bar{\psi} \wedge B)=\mathrm{Op}(A \wedge B) \wedge \psi
$$

In the case at hand, Henderson 2014 proposes that the variation condition is a postsupposition. For him, both components of meaning remain in situ, within the scope of the distributive operator. However, the postsupposed variation condition is evaluated only after the distributive scope has been closed off again, generating a plurality that can satisfy the postsupposition.

An analysis based on postsuppositions, however, is potentially problematic for empirical and theoretical reasons. First, I have argued that it is theoretically desirable to extend the analysis of dependent indefinites to same. On a postsuppositional analysis, however, such an extension gets into trouble with the boundary between falsity and undefinedness. Specifically, the adjective same bears a presupposed component and an at-issue component. The presupposed component (above, 'outside $(y / x)>1$ ') requires the existence of a plurality of events; as a presupposition, this component of meaning cannot be negated (as seen in the infelicity of (98a)), and generates ungrammaticality of the internal reading with singular subjects. The at-issue component (above, 'same $(y / x)$ ') compares entities to each other, and ensures that there is only one type or token involved; as an at-issue component, this can be negated (as in (98b)), and generates falsity when not satisfied.

(98) John bought and Mary sold the same book.

a. \# That's not true - Mary sold John a book; only one transaction occurred.

b. That's not true - John bought Harry Potter, but Mary sold The Great Gatsby.

Critically, both the presupposed component and the at-issue component of meaning need to be evaluated after the closure of the distributive scope. On the postsuppositional analysis, in which delayed evaluation is captured by a system designed for trivalence, there is no way to state the difference between the presupposition of same and its at-issue component: the failure to satisfy either is predicted to yield undefinedness. 
Second, in order to be backwards-compatible with Brasoveanu 2013's proposal with postsuppositions, Henderson is required to posit that postsuppositions are always be evaluated at the lowest distributive operator they scope under (see Henderson 2014, example 81). As a result, in sentences with two possible licensors that have a fixed scopal ordering, only one reading is predicted to be possible. In $\S 3$, we saw preliminary evidence involving dependent indefinites in Hungarian that suggests that this prediction is not borne out: namely, in sentences with two potential licensors, a dependent indefinite is able to associate with either licensor.

Conversely, an analysis with quantifier raising predicts that dependent indefinite licensing should be blocked by scope islands; as we will see in $\S 6.2$, this prediction is borne out. In contrast, this fact remains unexplained under an analysis with postsuppositions, which makes no such prediction.

Finally, there is a theoretical argument against postsuppositions on the grounds of parsimony: if we don't need them to capture the observed phenomenon, it's better not to add new technology to the compositional system. Needless to say, this final argument depends on the empirical adequacy of alternative theories; in light of the data to come in Sections 6.3 and 6.4, I thus put a correspondingly modest emphasis on this point.

\subsection{Predictions of QR: island effects}

In the proposal in Section 5, licensing by distributive operators is accomplished by letting a dependent indefinite take scope; scope-taking is analyzed as a case traditional quantifier raising. As is well known, quantifier raising obeys a number of constraints; under the proposal in $\S 5$, we thus expect these constraints to carry over to cases where dependent indefinites are licensed by distributive operators. Here, I will address predictions related to scope islands, bound pronouns, and coordination of dependent and plain indefinites.

Quantifier raising has been argued to be subject to scope islands: syntactic environments out of which distributive quantifiers cannot take scope (Fodor and Sag 1982). On the current analysis, dependent indefinites and same are analyzed as inherently distributive, so should be captured within such environments. Since licensing by distributive operators on my analysis requires taking scope over the licensor, this means that dependent indefinites and same are predicted to be unable to be separated from their licensor by an island boundary.

As it turns out, Carlson 1987 observes exactly this for English same: the internal reading of same is not licensed when an island boundary intervenes between same and its potential licensor. The sentences in (99) provide a minimal pair that illustrate this constraint. (Here, the relevant scope island - the antecedent of a conditional—is indicated with angled brackets.)

(99) a. Every professor said of the same student that if $\langle$ he graduated $\rangle$, it would be a stain on the university's reputation.

b. * Every professor said that if $\langle$ the same student graduated $\rangle$, it would be a stain on the university's reputation.

To my knowledge, no such tests have previously been reported for dependent indefinites. Nevertheless, it turns out that similar constraints hold in this domain as well. Sentences (100) 
and (101) provide Hungarian sentences analogous to the English sentences in (99), but with same replaced with the dependent indefinite két-két, 'two-two.' As for English same, the sentence is not grammatical when an island boundary intervenes between the dependent indefinite and its potential licensor. Sentence (102) provides a control for (101) without a dependent indefinite.

Hungarian (p.c. Márta Abrusán, three speakers)
Minden professzor két-két diákról mondta, hogy meglepné ha 〈diplomát szereznének〉. every professor two-two students-of said that surprised if diploma receive 'Every professor said of two students that he would be surprised if they graduated.'
(101) * Minden professzor azt mondta, hogy meglepné, ha 〈két-két diák diplomát szerezne〉. every professor DEM said that surprised if two-two student diploma receive 'Every professor said that he would be surprised if two students graduated.'
(102) Minden professzor azt mondta, hogy meglepné, ha 〈két diák diplomát szerezne〉. every professor DEM said that surprised if two student diploma recieve 'Every professor said that he would be surprised if two students graduated.'

These constraints fall out immediately from an analysis based on standard scope-taking, like the one provided in $\S 5$. In contrast, a postsuppositional analysis derives no principled reason why scope islands would delimit the evaluation of postsuppositions. These data thus provide evidence for an analysis of dependent indefinites based on fundamentally the same principles as scope elsewhere.

\subsection{Predictions of QR: bound pronouns}

It is well established that a bound pronoun must appear in the scope of its binder (Reinhart 1983, Barker 2012, among many others). As a consequence, when one quantifier binds a pronoun in the restrictor of another quantifier, the relative scope of the two quantifiers is fixed: the quantifier with the bound pronoun must scope below the pronoun's binder (see, e.g., Abusch 1994, Brasoveanu and Farkas 2011). For example, on a reading of (103) in which her is bound by every girl, the sentence only admits a reading in which the existential takes scope below the universal.

\section{(103) Every $^{i}$ girl invited one of her ${ }_{i}$ friends.}

$$
\checkmark \forall>\exists \quad * \exists>\forall
$$

On the analysis in $\S 5$, dependent indefinites and English same must take scope over a distributive operator in order to be licensed by it. Combined with the constraints on bound pronouns, this makes a specific prediction: dependent indefinites and same cannot be licensed by a distributive operator that binds into the restrictor of the dependent term.

Looking first at English same, this prediction indeed appears to be borne out: sentence (104) is ungrammatical on a reading in which his is bound by every boy. Specifically, the sentence cannot mean that there is one individual who is a friend of every boy and who was invited by every boy. ${ }^{9}$ 
* Every boy ${ }^{i}$ invited the same friend of his .

Turning to dependent indefinites, on the other hand, the situation is different. At least in Hungarian, a dependent indefinite can be licensed by a distributive operator that binds into the restrictor of the dependent indefinite. In (107), for example, the value of the NP filmjét, 'his films,' covaries with the directors, but the dependent indefinite is nevertheless licensed by the distributive operator minden rendezó, 'every director.'

(107) Hungarian (p.c. anonymous SALT reviewer; replication with two speakers)

Minden rendező benevezte két-két filmjét.

every director entered two-two his-films

'Every director entered two of his films.'

In order to capture this pattern, it seems that some mechanism of split scope is indeed necessary, with the pronoun scoping below the distributive operator (so that it can be bound) and the variation condition scoping above it (so that it has access to the plurality).

\subsection{Prediction of QR: coordination structures}

In $\S 3.3$, I presented a challenge for analyses in which dependent indefinites are licensed by the presence of a distributive operator. In two languages, we observed that a dependent indefinite can be coordinated with a plain indefinite that receives a cumulative reading (as repeated in (108)). This motivated an analysis in which a dependent indefinite remains in situ, with a quantificational component that distributes over the relevant parts of the plural licensor.

(108) Hungarian (p.c. Dániel Szeredi, four speakers)

A diákok két előételt és egy-egy főételt rendeltek.

The students two appetizers and one-one main-dish ordered

'The students ordered two appetizers one main dish.'

This insight was captured by the analysis given in $\S 5$ : in particular, for the sentence with a plural licensor in (82), note that the dependent indefinite remains in situ in the tree in (84).

On the other hand, Robert Henderson (p.c.) observes that this argument is a double-edged sword: the same properties that allow us to read off where the dependent indefinite is evaluated in (108) can also be employed to reveal where the dependent indefinite is evaluated with respect to a distributive licensor. As we have seen, the analysis above posits that dependent indefinites

\footnotetext{
${ }^{9}$ Interestingly, sentences of these form become grammatical when the NP containing the bound pronoun is given a functional reading, as in (105). Of note, though, Schwarz 2001 observes that these kinds of functional readings are not subject to the same binding constraints, as seen in the grammaticality of (106).

(105) Every boy ${ }^{i}$ invited the same relative of $\operatorname{his}_{i}$. (Namely, his mother.)

(106) No boy ${ }^{i}$ talks to a certain relative of his $i$ about girls. (Namely, his mother.)
} 
must take wide scope in order to be licensed by distributive operators. If a dependent indefinite is coordinated with a plain indefinite, the analysis thus makes the prediction that the plain indefinite must also take wide scope with respect to the distributive operator.

One such example is provided in (109); here, the plain indefinite két elótelt, 'two appetizers,' is coordinated with a dependent indefinite that is licensed by a distributive operator. The analysis above thus predicts that the plain indefinite should receive wide scope: namely, that there are a particular two (kinds of) appetizers that every student ordered. As it turns out, however, a natural reading of the sentence allows the chosen appetizers to vary with respect to the students - that is to say, the sentence allows a low-scope reading of the plain indefinite.

(109) Hungarian (three speakers)

Minden diák két előételt és egy-egy fóételt rendelt.

Every student two appetizers and one-one main-dish ordered.

'Every student ordered two appetizers and one main dish.'

Like the examples with bound pronouns, coordination constructions like the one in (109) require some component of meaning to take scope below the distributive operator; this is a second piece of evidence that some mechanism of split-scope is needed for dependent indefinites. ${ }^{10}$

\subsection{Theories of split-scope}

The findings reported in $\S 6.3$ and $\S 6.4$ show that dependent indefinites in at least some languages do indeed require a mechanism of split scope, so that the variation condition can scope outside of a distributive operator while another component of meaning remains below it. To this extent, the literature provides a number of different options.

Following Henderson 2014, we could adopt an enriched system with postsuppositions. Under such an analysis, the system presented in Section 5 could be simply modified to implement split-scope: the plurality condition outside $(y / x)=1$ becomes the postsupposition outside $(y / x)=1$. QR is not needed. All other aspects of the analysis of dependent indefinites remains the same. Note that this revision would retain the two fundamental architectural choices that I have argued for in this paper: namely, anaphoricity and inherent distributivity of dependent indefinites.

Nevertheless, we might remain skeptical that postsuppositions are the best mechanism for generating split scope, for the reasons sketched in $\S 6.1$ and $\S 6.2$ : namely, they confound trivalence and scope in the case of same, and they do not seem to make the correct predictions with respect to islands. Fortunately, the literature provides a variety of solutions in which split-scope is analyzed more on a par with 'standard' scope (e.g. Abels \& Martí 2010, i.a.).

\footnotetext{
${ }^{10}$ For English same, the situation is not so clear cut. My own English judgement is that the sentence in (110) is somewhat deviant, with an unclear meaning, but several other native English speakers report it to be acceptable on a reading in which appetizers vary with respect to boys but main dishes do not.
}

Every boy ordered two appetizers and the same main dish. 
For example, Abels \& Martí 2010 analyze split scope as QR with selective deletion, allowing a determiner to be interpreted high while its NP complement is evaluated low, restricting the values of the variable (for them a choice function) over which the determiner quantifies. Thus, the Hungarian sentence in (107), in which a distributive licensor binds into the restrictor of a dependent indefinite, would be assigned the logical form in (111); here, $t_{w}$ is restricted to range over only films by $x$, generating an interpretation equivalent to that in (112). The restrictor of the dependent indefinite is interpreted below the distributive operator so can be bound by it.

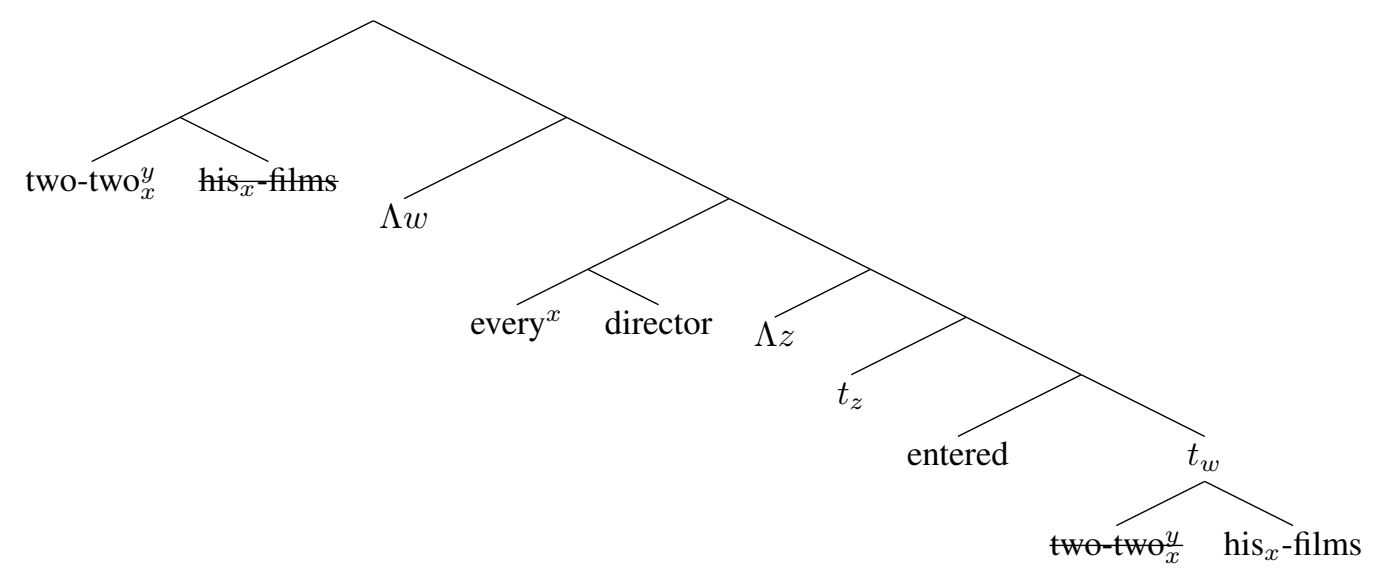

a. $[y] \wedge \max _{x}(\operatorname{DIRECTOR}(x)) \wedge$

$\delta_{x}($ FILMS-OF- $x(y) \wedge \operatorname{ENTERED}(y)(x)) \wedge$

$\operatorname{outside}(y / x)>1 \wedge \operatorname{inside}(y / x)=2$

Alternatively, Bumford 2016 provides a compositional dynamic fragment that captures splitscope phenomena by allowing the quantificational components of DPs to interleave with those of other DPs. This analysis dispenses with selective deletion and choice functions, and instead captures scope-taking using the 'continuations' of Barker 2001 and Barker and Shan 2008.

\section{Predictions of anaphoricity}

In Section 2, I argued that dependent indefinites are anaphoric to their licensors. This notion of 'anaphoricity' was initially construed very broadly, as the presence of a formal link between a dependent indefinite and its licensor. To illustrate how wide an umbrella this is, I consider this weak notion of anaphoricity to be satisfied by Barker's (2007) analysis of same in terms of parasitic scope. Under Barker's (2007) proposal, there are no covert indices or co-indexation; nevertheless, there is a formal link between the two constituents: same must move to a 'parasitic' syntactic position immediately below its licensor. (It bears mentioning that Barker and Shan 2014, building on Barker 2007, propose that pronoun binding, too, is achieved via parasitic scope, thus reinforcing what it means to be 'anaphoric' for such a framework.)

In the fragment presented in Section 5, the broad notion of anaphoricity is refined to a much more specific proposal: dependent indefinites retrieve their licensor through dynamic binding. This further refinement of the theory makes additional predictions. Here, I address two aspects 
of this proposal; I will argue that at least in the case of dependent indefinites in ASL, these predictions are correct.

\subsection{Crossover effects}

In general, a bound pronoun must appear at a structurally lower position than its binder. 'Crossover' describes the fact that this cannot be resolved by movement of the binder to a higher node, such as by wh-extraction or quantifier raising. A case of weak crossover is exemplified in (113); here, his is not in the scope of everyone, so cannot covary with respect to the quantifier, even though everyone can in principle undergo quantifier raising.

* $\operatorname{His}_{i}$ mother loves everyone ${ }^{i}$.

Under the analysis given above, dependent indefinites and adjectives like same are anaphoric to their licensor; we might thus expect them to be subject to crossover effects. However, Brasoveanu 2011, building on Barker 2007, observes that this is not the case. In particular, observe that (114) has fundamentally the same structure as (113): the anaphoric element appears at a higher structural position than its antecedent. Nevertheless, (114) is grammatical on an internal reading.

(114) The same $i$ waiter served everyone ${ }^{i}$.

The solution to this apparent puzzle is that crossover effects apply only to cases of quantificational binding; they do not carry over to dynamic binding, in which an pronoun may 'accidentally' pick up a discourse referent that is introduced in its scope. (115) provides an example: here, the pronoun his may be grammatically co-referent with John, without a violation of weak crossover.

(115) Even his mother loves John $^{i}$.

Under the analysis above, the connection between a dependent term and its licensor is achieved via dynamic (not quantificational) binding, so we do not predict any sensitivity to crossover effects, and sentences like (114) are correctly predicted to be grammatical. (A similar result holds for Brasoveanu's (2011) anaphoric proposal for singular different.)

\subsection{Cross-sentential anaphora}

The sentences discussed thus far focus predominantly on cases in which a dependent indefinite and its licensor appear in the same sentence. However, since the anaphoric relation between the two is captured through dynamic binding, the proposal above predicts that the licensor of a dependent indefinite need not scope over it, and may even appear a separate sentence. In ASL, this turns out to be a correct prediction.

In (116), the dependent indefinite 'ONE-redup STUDENT' shows agreement not with the distributive operator that appears in the same sentence, but rather with 'MANY CLASSES,' a 
plural in a separate sentence. Nevertheless, the sentence is judged as grammatical, with the truth conditions that Professor X nominated one student per class, Professor Y nominated one student per class, and so on.

MY SCHOOL HAS [MANY CLASSES]-b. EACH-a PROFESSOR NOMINATE ONE-redup-b STUDENT.

'My school has many classes. Each professor nominated one student per class.'

This is exactly the meaning that the analysis above would predict: namely, that each given professor nominated a plurality of students, one associated with each class.

This being said, note that cases of cross-sentential licensing of dependent indefinites like the one above require a certain degree of pragmatic reasoning in order to infer what the relevant function is between the licensor and the plurality introduced by the dependent indefinite. In the case of sentence-internal licensing, the compositional apparatus immediately provides this functional association-essentially, it is the complex predicate that relates the two arguments. On the other hand, when there is no structural relation between a dependent indefinite and its licensor, the association must be constructed from context.

In fact, the cost of this process can be illustrated in English sentences with the 'per NP' construction, which roughly approximates the meaning of a dependent indefinite with a contextual licensor. In (117a), parallel to the ASL sentence in (116), the class-student association is easily accommodated; in (117b) on the other hand, the lack of an obvious association between girls and popsicles makes the sentence deviant without significantly more context.

(117) a. I nominated two students per class.

b. ? I ate two popsicles per girl.

Although I am not aware of any examples from spoken language that directly address the prediction of cross-sentential licensing for dependent indefinites, the role of pragmatic reasoning in cases like (116) is evocative of Cable 2014's use of 'cognitively natural' partitions in his analysis of dependent indefinites in Tlingit, which may be used without an overt licensor to express distribution of a plurality across time or space, but not over such contextual properties as, for example, what clothing people are wearing. I leave as an open question the more systematic comparison of sign and spoken language in this regard, including the possible role that spatial agreement plays in facilitating the retrieval of a functional association from context.

\section{Summary}

In this paper, I discussed a variety of dependency constructions in natural language, focusing on the case of dependent indefinites, where inflection indicates that the value of one DP varies with respect to another plurality in the sentence. Compositionally, these constructions pose an interesting challenge by virtue of the long-distance relationship between the dependent indefinite and its licensor. The nature of what can serve as a licensor also provides a puzzle: across many 
languages, dependent indefinites are licensed by plural nouns but not by singulars; yet they also can be licensed by operators that distribute down to atomic individuals. Here, I adopted Plural Compositional DRT as an attractive framework in which to analyze these kinds of constructions, since PCDRT allows the compositional semantics to keep track of dependency relations between plural discourse referents.

Analyses of dependent indefinites vary with respect to several architectural questions. First, an analysis must explain the relation between a dependent indefinite and its licensor. On some analyses, this connection is direct (i.e. anaphoric); in others, it arises indirectly through the compositional semantics. Second, an analysis must explain the fact that both plurals and distributive operators can serve as licensors. When plural licensors are taken to be the base case, dependent indefinites under distributive operators are redundantly vacuous; when distributive operators are taken to be the base case, dependent indefinites under plurals must be licensed by a covert distributivity operator. Finally, an analysis must explain the semantic mechanism that allows dependent indefinites to be licensed by operators that distribute down to atomic individuals, but not by singular nouns.

I argued that the patterns of dependent indefinites in American Sign Language give insight into these questions. Based on the fact that dependent indefinites in ASL show spatial agreement with their licensor, I proposed that dependent indefinites include an anaphoric component (following Brasoveanu and Farkas 2011). Based on the fact that dependent indefinites in ASL are morphologically unified with SAME and DIFFERENT, I argued that dependent indefinites have a similarly quantificational semantics (following Balusu 2006 and Cable 2014).

These two design choices result in more theoretical freedom along certain other dimensions. First, plural nouns are able to license dependent indefinites without the need for a covert distributivity operator; this freed us from a challenge regarding the coordination of plain and dependent indefinites. Second, the variation condition is able to escape from the distributive scope of an operator without the need for postsuppositions: I provided an analysis in which dependent indefinites take wide scope through standard scope-taking mechanisms.

\section{Acknowledgements}

This work would not be possible without the ASL consultants involved; in particular, I would like to thank Jonathan Lamberton for helpful insight throughout the project. The analysis presented here is due in large part to discussion with Philippe Schlenker, Dylan Bumford, and Chris Barker. Thank you to Dániel Szeredi, Ildikó Szabó, and Márta Abrusán for help with Hungarian examples. The research leading to these results received funding from the European Research Council under the European Union's Seventh Framework Programme (FP/2007-2013) / ERC Grant Agreement N³24115-FRONTSEM (PI: Schlenker). Research was conducted at Institut

d'Etudes Cognitives (ENS), which is supported by grants ANR-10-IDEX-0001-02 PSL* and ANR-10-LABX-0087 IEC. 


\section{References}

Abels, K. and Martí, L. (2010). A unified approach to split scope. Natural Language Semantics, 18(4):435-470.

Abusch, D. (1994). The scope of indefinites. Natural Language Semantics, 2(2):83-135.

Balusu, R. (2005). Distributive reduplication in Telugu. In Davis, C., Deal, A. R., and Zabbal, Y., editors, Proceedings of the 36th Annual Meeting of the North East Linguistic Society (NELS 36), pages 39-53, Amherst, MA. University of Massachusetts GLSA Publications.

Barker, C. (2001). Introducing continuations. In Hastings, R., Jackson, B., and Zvolenszky, Z., editors, Proceedings of the 11th Semantics and Linguistic Theory Conference (SALT 11), pages 20-35, Ithaca, NY. Cornell University.

Barker, C. (2007). Parasitic scope. Linguistics and Philosophy, 30(4):407-444.

Barker, C. (2012). Quantificational binding does not require c-command. Linguistic inquiry, 43(4):614-633.

Barker, C. and Shan, C.-c. (2008). Donkey anaphora is in-scope binding. Semantics and Pragmatics, 1:1-46.

Barker, C. and Shan, C.-c. (2014). Continuations and natural langauge. Oxford University Press, Oxford, UK.

Bauman, C., Holliday, N., LaFave, N., Lin, K., Martin, S., and Shapp, A. (2012). Every sentence has how many quantifiers each? binominal each in English. In Mid-Atlantic Colloquium of Studies in Meaning 2, College Park, MD. University of Maryland.

Beghelli, F. and Stowell, T. (1997). Distributivity and negation. In Szabolcsi, A., editor, Ways of Scope Taking, pages 71-109. Dordrecht: Kluwer.

Brasoveanu, A. (2006). Structured Nominal and Modal Reference. PhD thesis, Rutgers University.

Brasoveanu, A. (2008). Donkey pluralities: Plural information states vs. non-atomic individuals. Linguistics and Philosophy, 3(2):129-209.

Brasoveanu, A. (2011). Sentence-internal different as quantifier-internal anaphora. Linguistics and Philosophy, 34(2):93-168.

Brasoveanu, A. (2013). Modified numerals as post-suppositions. Journal of Semantics, 30(2):155-209.

Brasoveanu, A. and Farkas, D. (2011). How indefinites choose their scope. Linguistics and philosophy, 34(1):1-55. 
Bumford, D. (2016). Split-scope definites: Relative superlatives and haddock descriptions. Ms. New York University.

Bumford, D. and Barker, C. (2013). Association with distributivity and the problem of multiple antecedents for singular different. Linguistics and Philosophy, 36:355-369.

Cable, S. (2014). Distributive numerals and distance distributivity in Tlingit (and beyond). Language, 90(3):562-606.

Carlson, G. N. (1987). Same and different: Some consequences for syntax and semantics. Linguistics and Philosophy, 10(4):531-565.

Champollion, L. (2015). Every boy bought two sausages each: Distributivity and dependent numerals. In Steindl, U., Borer, T., Fang, H., Pardo, A. G., Guekguezian, P., Hsu, B., O'Hara, C., and Ouyang, I. C., editors, Proceedings of the 32nd West Coast Conference on Formal Linguistics (WCCFL 32), pages 103-110, Somerville, MA. Cascadilla Proceedings Project.

cil, J. D. (2011). Fastidious distributivity. In Ashton, N., Chereches, A., and Lutz, D., editors, Proceedings of the 21st Semantics and Linguistic Theory Conference (SALT 21), pages 313332.

Dekker, P. (1993). Transsentential meditations: ups and downs in dynamic semantics. $\mathrm{PhD}$ thesis, University of Amsterdam.

Dowty, D. and Brodie, B. (1984). The semantics of floated quantifiers in a transformationless grammar. In MacKaye, Cobler, and Wescoat, editors, Proceedings of the 3rd West Coast Conference on Formal Linguistics (WCCFL 3). Stanford.

Farkas, D. F. (1997). Dependent indefinites. In Corblin, F., Godard, D., and Marandin, J.-M., editors, Empirical issues in formal syntax and semantics, pages 243-268, Bern, Switzerland. Peter Lang.

Farkas, D. F. (2001). Dependent indefinites and direct scope. In Condoravdi, C. and Renardel, G., editors, Logical perspectives on language and information, pages 41-72. CSLI Publications, Palo Alto, CA.

Farkas, D. F. (2002). Extreme non-specificity in romanian. In Beyssade, C., editor, Romance languages and linguistic theory 2000, pages 127-151. John Benjamins, Amsterdam, Netherlands.

Fodor, J. D. and Sag, I. (1982). Referential and quantificational indefinites. Linguistics and Philosophy, 5(3):355-398.

Groenendijk, J. and Stokhof, M. (1991). Dynamic predicate logic. Linguistics and Philosophy, 14(1):39-100. 
Hardt, D. and Mikkelsen, L. (2015). Same but different. Linguistics and Philosophy.

Hardt, D., Mikkelsen, L., and Ørsnes, B. (2012). Sameness, ellipsis and anaphora. In Aloni, M., Kimmelman, V., Roelofsen, F., Sassoon, G. W., Schulz, K., and Westera, M., editors, Logic, Language and Meaning: 18th Amsterdam Colloquium, pages 341-350, Amsterdam, Netherlands. Springer Berlin Heidelberg.

Heim, I. (1990). E-type pronouns and donkey anaphora. Linguistics and Philosophy, 13(2):137178.

Henderson, R. (2014). Dependent indefinites and their post-suppositions. Semantics and Pragmatics, 7(6):1-58.

Kadmon, N. and Landman, F. (1993). Any. Linguistics and Philosophy, 16(4):353-422.

Kimmelman, V. (2015). Distributive quantification in russian sign language. In Formal and Experimental Advances in Sign Language Theory, Barcelona, Spain.

Kuhn, J. (2015). Cross-categorial singular and plural reference in sign language. $\mathrm{PhD}$ thesis, New York University.

Landman, F. (2000). Events and plurality: The Jerusalem lectures. Kluwer, Dordrecht, Netherlands.

Lillo-Martin, D. and Klima, E. (1990). Pointing out differences: ASL pronouns in syntactic theory. Theoretical Issues in Sign Language Research, 1:191-210.

Nouwen, R. (2003). Plural pronominal anaphora in context: Dynamic aspects of quantification. PhD thesis, Utrecht University, Utrecht, Netherlands.

Nunberg, G. (1984). Individuation in context. In Proceedings of the 3rd West Coast Conference on Formal Linguistics, pages 203-217. Stanford Linguistics Association.

Oh, S.-R. (2006). Plurality markers across languages. PhD thesis, University of Massachusetts, Amherst, MA.

Pfau, R. and Steinbach, M. (2006). Pluralization in sign and in speech: A cross-modal typological study. Linguistic Typology, 10:135-182.

Reinhart, T. (1983). Anaphora and semantic interpretation. University of Chicago Press, Chicago, IL.

Roberts, C. (1987). Modal Subordination, Anaphora, and Distributivity. PhD thesis, University of Massachusetts, Amherst.

Rushiti, B. (2015). Distance-distributivity in albanian: the distributive marker $n g a$. Presentation for seminar on co-distributivity. 
Schlenker, P. (2011). Donkey Anaphora: the View from Sign Language (ASL and LSF). Linguistics and Philosophy, 34(4):341-395.

Schwarz, B. (2001). Two kinds of long-distance indefinites. In Van Rooij, R. and Stokhof, M., editors, Proceedings of the 13th Amsterdam Colloquium, pages 192-197, Amsterdam, Netherlands. ILLC Publications.

Schwarzschild, R. (1996). Pluralities. Kluwer, Dordrecht, Netherlands.

Szabolcsi, A. (2010). Quantification. Cambridge University Press, Cambridge, UK.

van den Berg, M. (1996). Some aspects of the internal structure of discourse: the dynamics of nominal anaphora. PhD thesis, ILLC, Universiteit van Amsterdam.

Wilbur, R. (1973). The phonology of reduplication. PhD thesis, University of Illinois, UrbanaChampaign.

Yanovich, I. (2005). Choice-functional series of indefinite pronouns and hamblin semantics. In Proceedings of the 15th Semantics and Linguistic Theory Conference (SALT 15), volume 15, pages 309-326, Ithaca, NY. Cornell University CLC Publications. 